\title{
EXCAVATIONS AT MOTZA \\ IN THE JUDEAN HILLS AND THE EARLY \\ PRE-POTTERY NEOLITHIC B \\ IN THE SOUTHERN LEVANT
}

\author{
H. KHALAiLy, O. BAR-YOSEF, O. BARZILAI, E. BOARETTO, F. BOCQUENTIN, \\ A. EIRIKH-ROSE, Z. GREENHUT, A.N. GORING-MORRIS, G. LE DOSSEUR, O. MARDER, \\ L. SAPIR-HEN and M. YIZHAQ
}

\begin{abstract}
Recent excavations at Motza near Jerusalem revealed a large Neolithic site that was continuously inhabited from the Early $P P N B$ until the Pottery Neolithic period. The well-dated Early PPNB occupation comprises various architectural remains, human burials, clay and stone figurines, and rich flint and obsidian assemblages. Layer VI is approximately $2 \mathrm{~m}$ thick and consists of three discrete occupational levels with distinct architectural remains. These include curvilinear and rectangular structures with lime plastered floors, courtyards, hearths, and long massive walls of up to $1 \mathrm{~m}$ width. This layer is dated by sixteen radiocarbon dates, all falling within the range of 8600-8200 cal. BC. The EPPNB flint assemblage at Motza demonstrates a combination of the continuation of the earlier PPNA traditions together with the introduction of new technological innovations. The formal tools are dominated by Helwan and Jericho points, with many of the former being made on bidirectional blades in the north Levantine mode. Sickle blades are also mainly fashioned on bidirectional blanks. Mountain gazelle (Gazella gazella), the dominant species of the EPPNB faunal remains, indicates that hunting was still important. Gazelle bones were preferred for manufacturing bone tools, continuing PPNA Sultanian practices. Most of the human remains were primary burials, with no preference in the orientation of the bodies, although they were tightly flexed. Graves illustrate various funerary practices although primary inhumations on tightly flexed position are more common. All three primary graves of adults show evidence of later skull removal. Corpse treatment seems nonetheless quite particular at Motza as most of the graves were associated in different ways with remains of plaster, more frequently, as patches mixed in the filling of the grave. The archaeological evidence from Motza revises the hypothesis held by some that the PPNB in this region only started in the MPPNB. In addition, the advanced naviform technology and Helwan points present at Motza appear to be chronological markers of this period and together with radiocarbon dates confirm the existence of this stage of the PPNB in the southern Levant.
\end{abstract}

\begin{abstract}
Résumé : Les fouilles effectuées récemment à Motza, près de Jérusalem, ont révélé la présence d'un important site néolithique occupé de manière continue du PPNB ancien au Néolithique céramique. Bien datée, l'occupation du PPNB ancien a livré de nombreux vestiges architecturaux, des sépultures, des figurines d'argile et de pierre, ainsi qu'une abondante industrie sur silex et obsidienne. Le niveau 6, épais de près de deux mètres, comporte trois couches d'occupation successives, présentant des restes architecturaux distincts. Ceux-ci incluent des structures curvilinéaires et rectangulaires avec des sols de chaux, des cours, des foyers et des murs massifs de plus d'un mètre d'épaisseur. Cette couche est datée par seize datations radiocarbone toutes comprises entre 8600 et 8200 av. J.-C. (cal.). L'industrie lithique de Motza présente une combinaison de traditions plus anciennes du PPNA associées à des innovations technologiques. Les pointes d'Helwan et de Jéricho dominent l'outillage et beaucoup sont façonnées sur des lames bidirectionnelles comme au Levant Nord. La plupart des lames de faucilles sont elles aussi façonnées sur des produits bipolaires. La gazelle (Gazella gazella) qui domine l'assemblage faunique du PPNB ancien indique que la chasse reste importante à cette période. La gazelle sert préférentiellement de support pour l'industrie osseuse, un choix hérité du Sultanien. Les pratiques funéraires sont variées, mais les inhumations sont majoritairement primaires et la position sur le côté en flexion forcée domine. Dans les trois inhumations primaires d'adultes, les crânes ont été prélevés après décomposition. Le traitement des corps observé à Motza se singularise par la présence de plâtre associé aux sépultures de diverses manières, particulièrement des morceaux mêlés au remplissage. Les découvertes faites à Motza invitent à revoir
\end{abstract}


l'hypothèse selon laquelle, dans cette région, le PPNB n'aurait débuté qu'avec sa phase moyenne (MPPNB). De plus, la technologie naviforme évoluée et les pointes d'Helwan présentes à Motza, apparaissent comme des marqueurs chronologiques de cette période ; associées aux datations $C^{14}$, elles confirment l'existence de cette phase ancienne du PPNB au Levant Sud.

Keywords: Motza, PPNA, EPPNB, Southern Levant, Plaster, Helwan Points, Bidirectional Blade Technology, Cache, Burial Custom, Mountain Gazelle.

Mots-clés: Motza, PPNA, EPPNB, Levant Sud, Plâtre, Pointes d'Helwan, Débitage laminaire bidirectionnel, Cache, Pratiques funéraires, Gazelle.

The transition from the Pre-Pottery Neolithic A (herein PPNA) to the Pre-Pottery Neolithic B (PPNB) was until recently poorly documented due to the lack of well excavated and dated sites. ${ }^{1}$ Nevertheless, the recent publications of sites on the middle Euphrates in the northern Levant, at Jerf elAhmar and Cheikh Hassan, have supported Cauvin's suggestion of cultural continuity there between these periods. ${ }^{2}$ The basis for this recognition was embedded in initial PPNB occupation levels dated to the time slot between 8800-8200 cal. BC.

The indisputable presence of Early PPNB (EPPNB) in the northern Levant led several scholars to argue that this stage exists only in the north, while its presence in the south was doubtful, with some even questioning its very existence. ${ }^{3}$ Indeed, on the basis of investigations at the late PPNA site of Zahra adh-Dhra 2, adjacent to the Dead Sea, it was recently claimed that the PPNA in the southern Levant continued until ca 8400 cal. BC, thus negating the existence of the EPPNB in the Southern Levant. ${ }^{4}$ By contrast, other scholars believe that this stage is well represented in the southern Levant. ${ }^{5}$

A major problem in this debate has been rooted in the small number of radiocarbon dates available from excavated sites attributed to this stage and uncertainties concerning some of those dates ${ }^{6}$, in particular during the period between 8500 8100 cal. BC.

In the following paper, we present the results of two seasons of excavation at Motza, in the Judean hills, that yielded finds clearly demonstrating the existence of the EPPNB in

1. KUIJT, 2003; KUIJT and GORING-MORRIS, 2002: 382.

2. ABBÈS, 2003; CAUVIN, 1968 et 2000; STORDEUR, 1999; STORDEUR et ABBÈS, 2002.

3. Cauvin, 2000; Cauvin et CaUvin, 1993; KuiJt, 1997 and 2003; STORDEUR et ABBÈS, 2002.

4. EDWARDS et al., 2002: 11 and 2004: 45.

5. BAR-YOSEF, 1981; GOPHER, 1989a and 1996; GOPHER and GOPHNA, 1993; GORING-MORRIS and BELFER-COHEN, 1997; GORING-MORRIS in KUIJT and GORING-MORRIS, 2002.

6. EDWARDS et al., 2004. the southern Levant. This is based on both the composition of the material culture remains, as well as on more than a dozen radiocarbon dates. The thickness of the EPPNB deposits and successive construction phases make Motza one of the major EPPNB sites in the southern Levant.

\section{ENVIRONMENT AND HISTORY OF RESEARCH}

The site of Motza is located $5 \mathrm{~km}$ west of Jerusalem, on the western bank of Nahal Soreq, ca $600 \mathrm{~m}$ asl, west of the watershed of the Judean and Samarian hills (fig. 1). Nahal Soreq is one of the principle westward flowing wadis in the Judean hills. The surrounding landscape is determined mainly by the local drainage system, which dissects the area into three main features. Motza is situated on the rift between the Mevaseret ZionRamot ridge from the north and the Motza Ilit ridge from the south. ${ }^{7}$ The Soreq valley is a major, deeply incised topographic feature in the area, broadening downstream into a wide fertile valley suitable for cultivation. ${ }^{8}$ The valley also provides relatively easy access to the Shephelah and the coastal plain to the west, and to the watershed of the central hill ridge and thence to the Rift valley just north of the Dead Sea in the east.

The site is located on a relatively steep, south-facing spur above the wadi course..$^{9}$ Abundant springs existed along both valleys (Motza and Soreq), two of which are still active near the site. These optimal conditions were clearly a main factor in the long occupation sequence at the site, extending from the Epipalaeolithic (Kebaran) until recent times. ${ }^{10}$

7. EFRAT, 1963; MARKUS, 1993

8. The valley also dictates the route of the modern Jerusalem-Tel Aviv highway, which runs at the foot of the site.

9. ING 215600/633400.

10. MARDER and KHALAILY, 2004. 
Several earlier excavations were conducted at the site uncovering remains dating from the Early Bronze Age I onwards. ${ }^{11}$ The present excavations were initiated in 2002 and 2003 as a salvage project for road construction. ${ }^{12} \mathrm{~A}$ total of $150 \mathrm{~m}^{2}$ were excavated, divided into northern and southern sectors, $20 \mathrm{~m}$ apart (fig. 2).

\section{STRATIGRAPHY AND ARCHITECTURE} [H.K. and Z.G.]

The 2002 and 2003 seasons revealed five archaeological layers, three of which date to the Neolithic period. The remains include walls, fragments of rooms, living spaces, installations, and burials. Figure 3 presents a type section of the archaeological layers, including a sedimentological unit indicating the various phases of each layer. ${ }^{13}$

Layer I. This uppermost layer ( $c a$ 0.8-1.2 m thick) constituted Ottoman period agricultural terraces covering Iron Age remains; some of the Iron Age silos and pits were dug deep into the PPNB layers.

Layer II. Layer II is a thin, ca $0.4 \mathrm{~m}$, Middle Bronze Age II layer, present in both sectors.

Layer III. This EB Ia layer, ca $0.4 \mathrm{~m}$ thick, was exposed mainly in the northern sector.

Layer IV. Layer IV, dating to the Late Neolithic, was exposed mainly in the northern sector, remains being scarce in the southern sector. The fill contained dark grey clay mixed with small gravel and abundant lithics, a few Neolithic sherds, and many faunal remains. Archaeobotanical remains were wellpreserved. Several wall segments and installations were noted in the northern sector. A line of three standing stones, most probably masseboth, were associated with one wall segment. A pit, as well as two small stone-paved hearths and another hearth lined with small stones were discovered. A possible constructed pillar base was also uncovered. Several typical

11. Neolithic flints had already been collected from the area in 1927 (SHALEM, 1928 and 1937) and these were confirmed in the early 1960s by Bar-Yosef; however, it was difficult to pinpoint the exact location of the occupation. During excavations of an Iron Age settlement in 1993 the presence of Neolithic flints were recorded, although they were found out of context (GROOT (DE) and GREENHUT, 1995). More recently, in a deep sounding conducted adjacent to the Jerusalem-Tel Aviv highway, a LPPNB stratum was briefly investigated under the remains of a Byzantine building (EISENBERG and SKLAR, 2005).

12. The excavations were directed by three of the authors [HK, ZG and AIR] on behalf of the Israel Antiquities Authority. The excavated area directly underlies remains exposed during the 1993 season.

13. For details of the upper, pre-Neolithic levels see GREENHUT, 2006.
Late Neolithic vessels were scattered on the beaten earth floor. In addition, a huge pit was exposed containing ashes mixed with small dark stones and numerous flints and sherds. These indicate that the pit probably postdates Layer IV, and can be assigned to the Late Neolithic Wadi Rabah culture. The rest of Layer IV can be dated slightly earlier, to the Jericho IX phase, as based on the material culture remains and two radiometric dates.

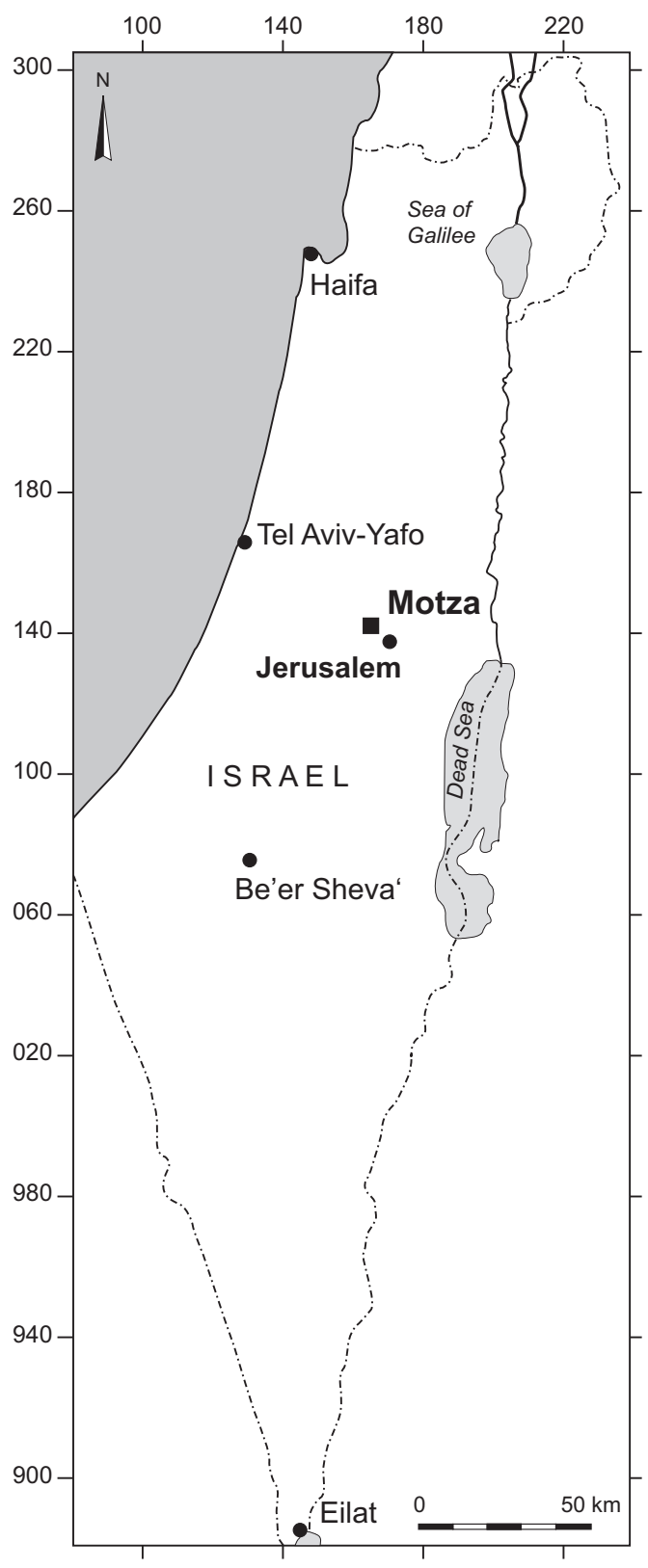

Fig. 1: Location map. 


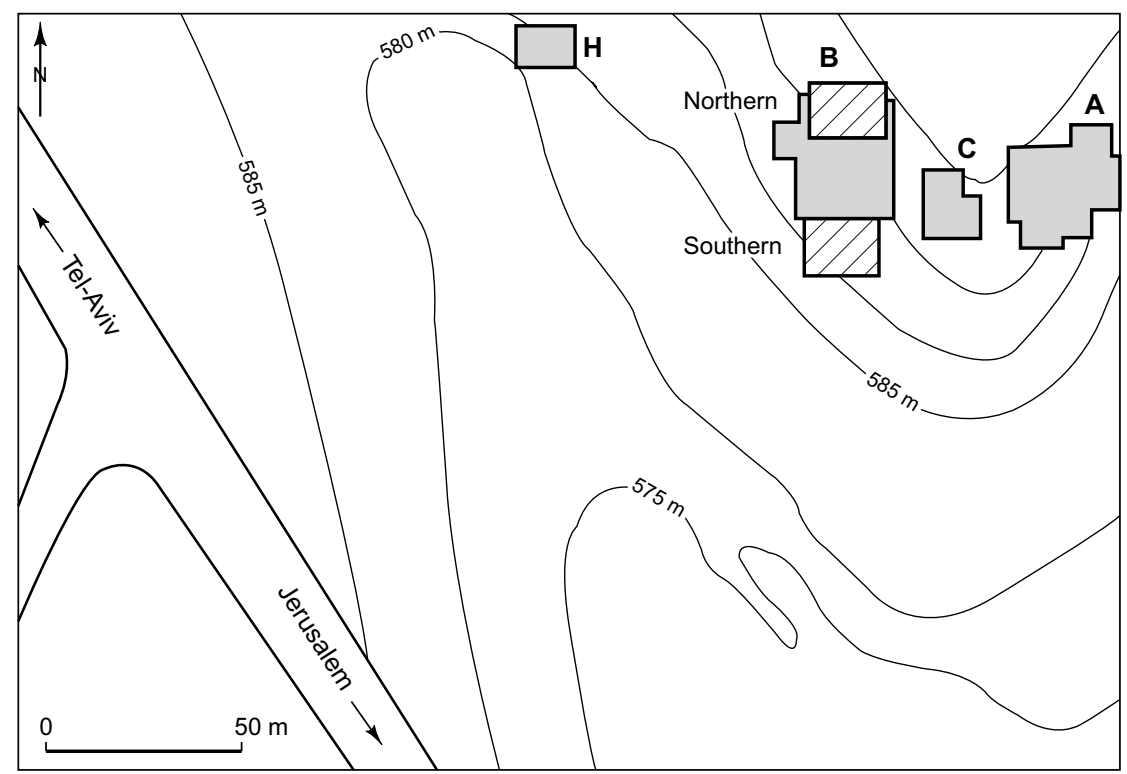

Fig. 2: Excavation areas.

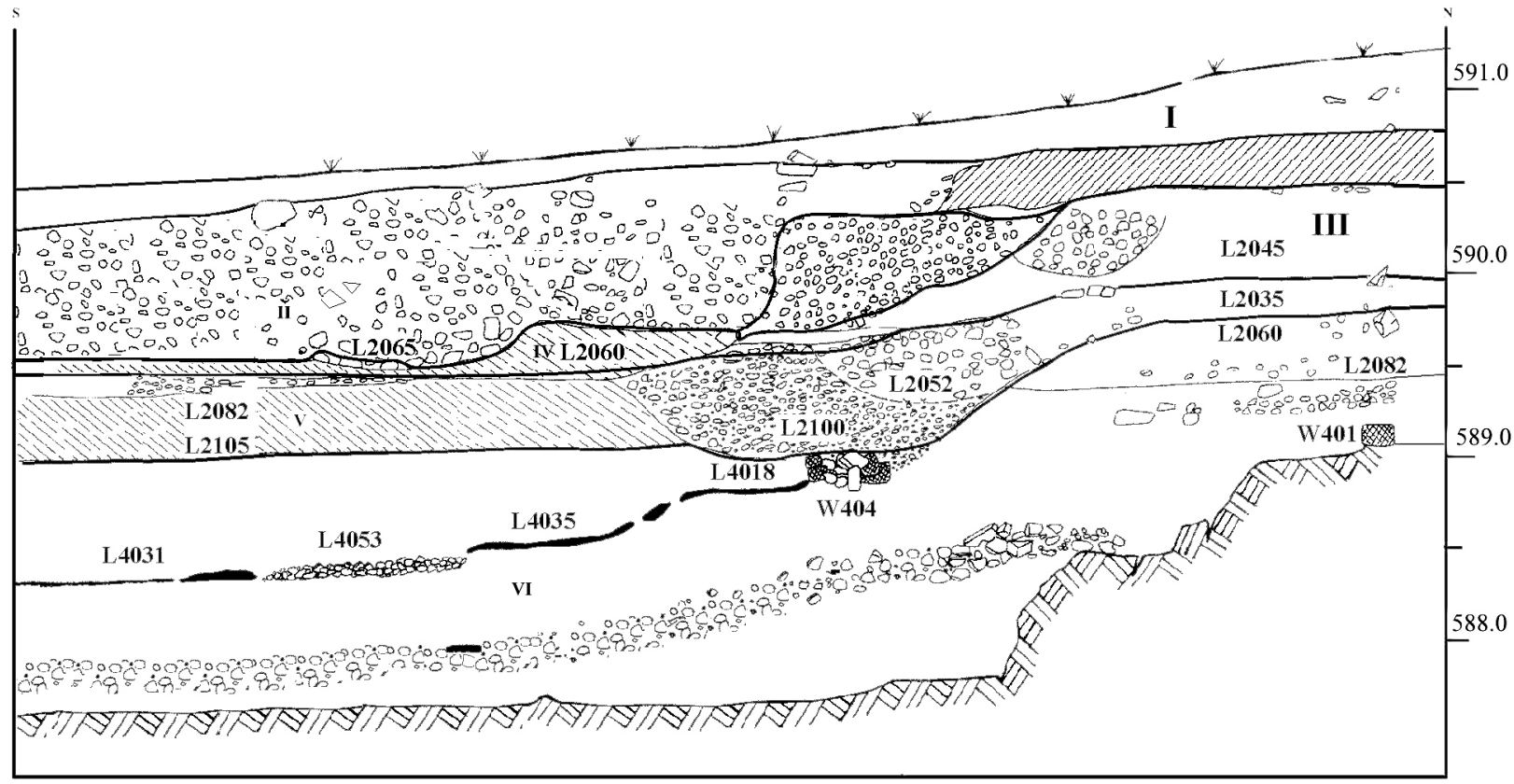

Fig. 3: Main section.

Layer V. This Middle PPNB layer was exposed in both sectors, although it was thicker in the northern sector ( $c a 1.5 \mathrm{~m}$ ) than in the south, where they were truncated by the foundations of an Iron Age building. Layer V comprised three construction phases: the upper phase included gravel surfaces, plaster floors, pits, wall segments and a constructed installation; the middle phase included two installations, gravel surfaces and wall fragments; the lowest phase was better preserved and included MPPNB rectangular structures constructed with stone walls, plastered floors, installations and waste pits. Under one 


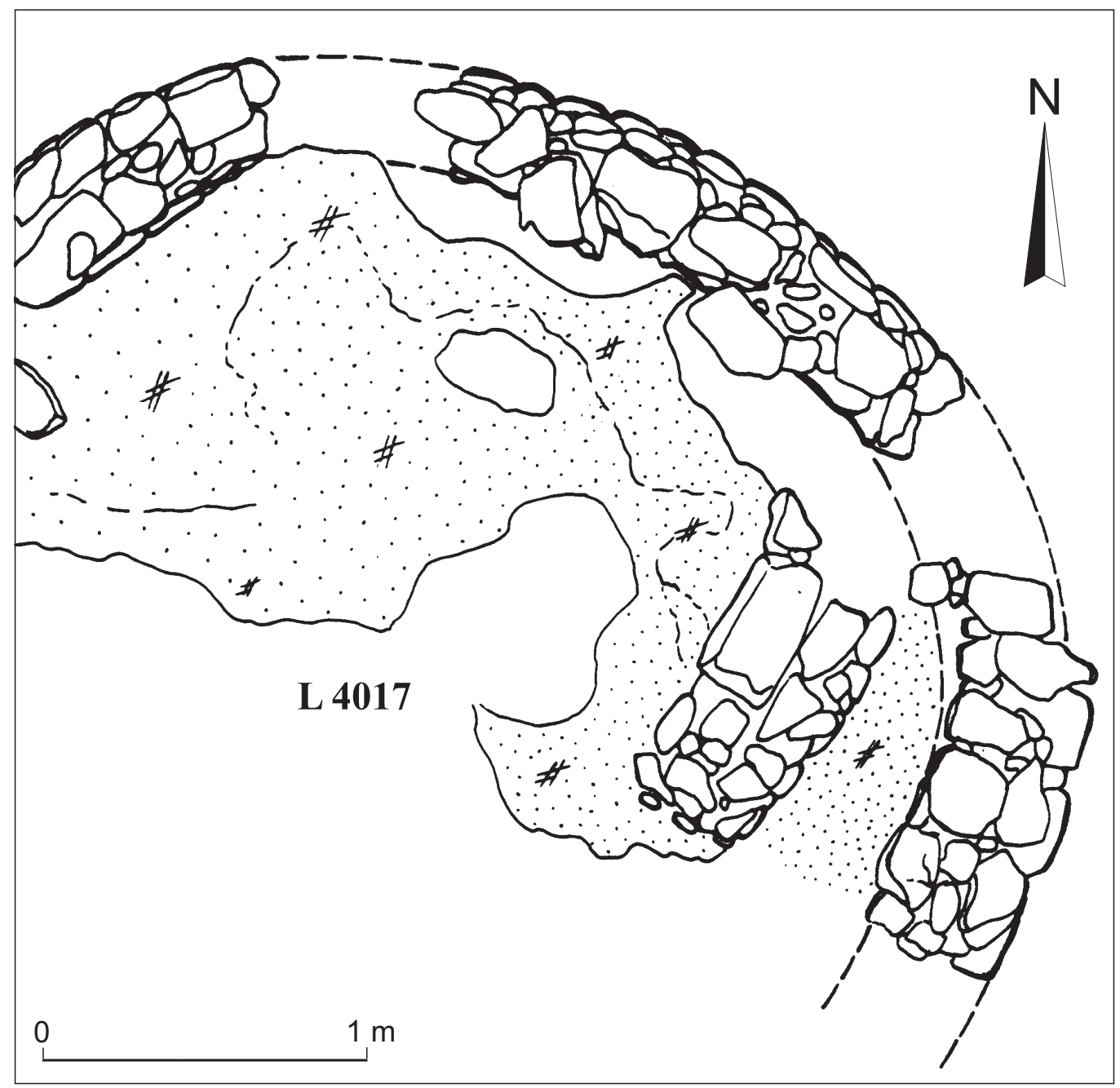

Fig. 4: Plan of rounded structure.

plastered floor an infant burial was found. In the southern sector patches of plastered floors, wall segments and a pit were revealed in all three phases. Three ${ }^{14} \mathrm{C}$ dates were obtained.

Layer VI. Remains of an EPPNB layer, ca 2 m thick, were uncovered in both sectors, directly on the bedrock. The deposit ranges from light brown to dark brown clay indicating three occupational phases within the EPPNB layer, each with distinctive architectural remains.

The excavations of the upper phase of the northern sector revealed several poorly preserved architectural features, including a red painted plaster-floored, curvilinear structure (fig. 4). Nearby was a large pit, L4005, containing remains of several partially articulated Bos primigenius. In addition, several wall fragments, three installations and a burial were documented.
The middle phase yielded various architectural features, burials, hearths and installations. In the northern sector a quadrilateral building was exposed (fig. 5). The building technique included stone and mudbrick for the outer walls and lime plastered floors. Adjacent to the building several primary and secondary burials were located, together with a flint cache, L4069 (see below).

The lower phase in the northern sector was identified directly over the bedrock and contained wall segments and stone heaps.

The remains in the southern sector were similar to those in the northern. The upper phase included plaster-floored structures, open areas, hearths, and burials (see below). In the middle phase a massive wall (fig. 6) bisected the area from northwest to southeast and may have been part of a large 


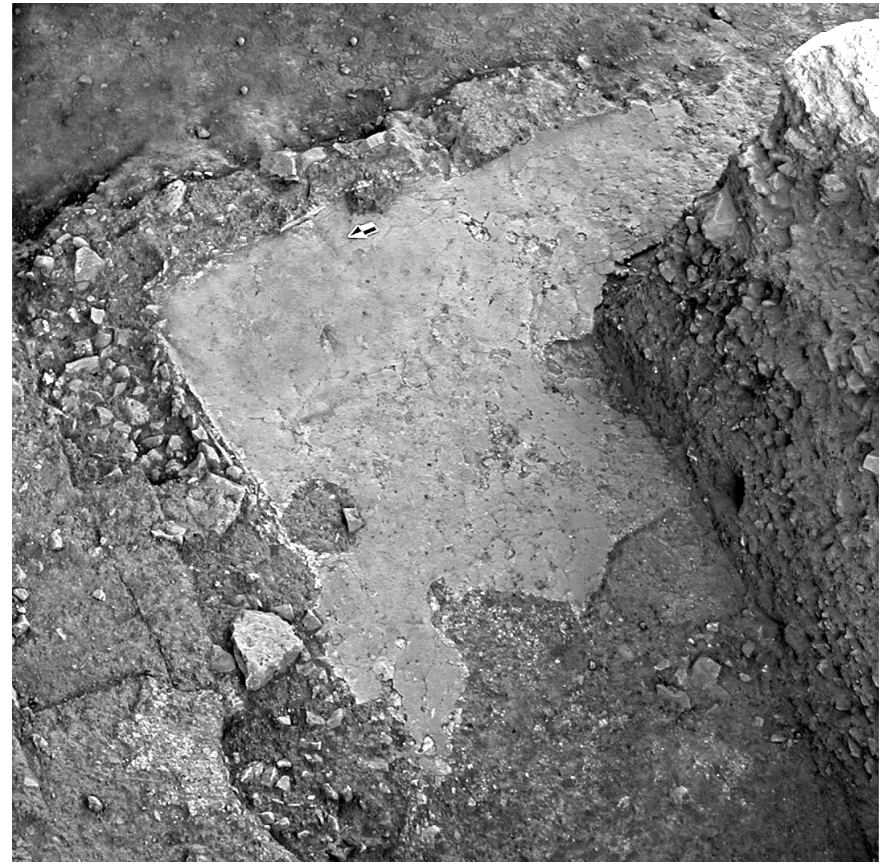

Fig. 5: Rectangular house in upper section.

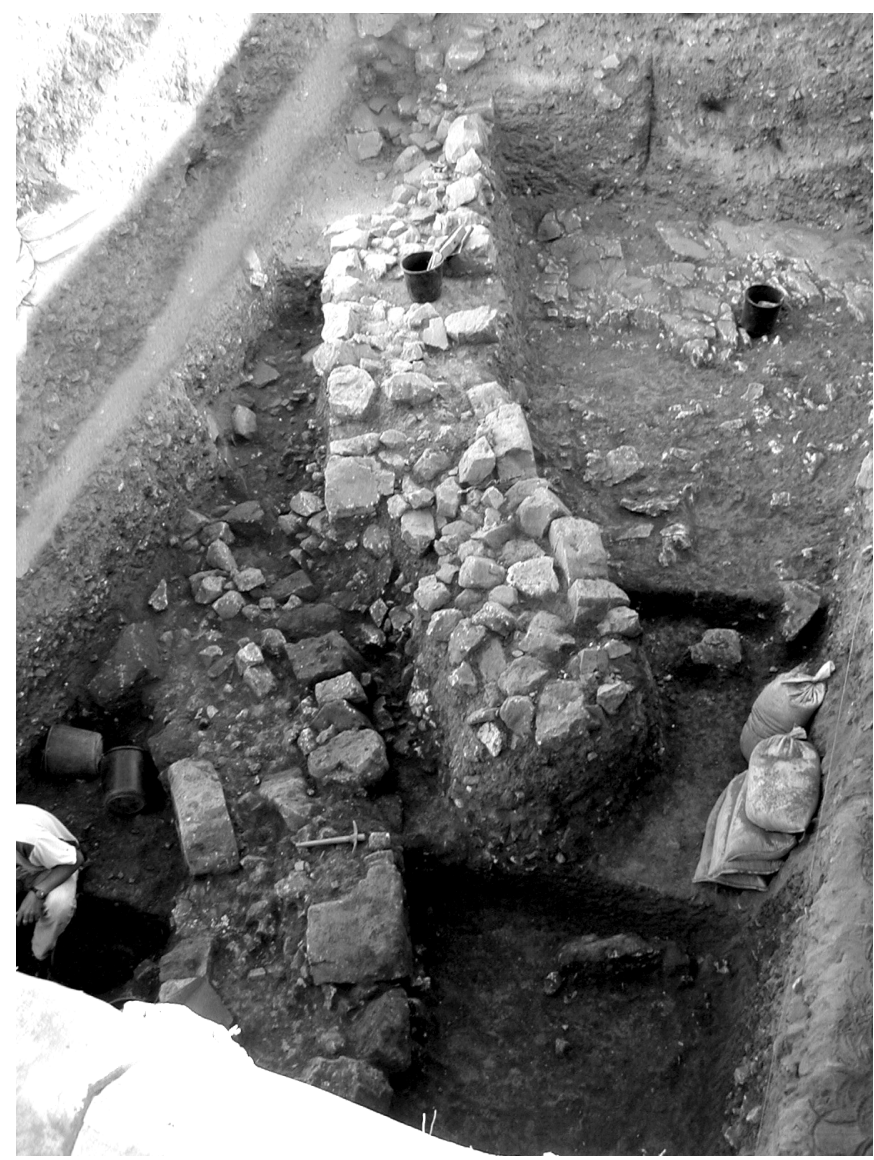

Fig. 6: Lower section, two massive walls. building. An additional massive curved wall was the earliest and lowest feature in the southern sector ( $c a 8 \mathrm{~m}$ diameter). This massive segment was placed directly on the bedrock and it seems that it was part of a round architectural feature.

The material culture includes a rich lithic assemblage dominated by Helwan and Jericho points. Most of the sickle blades are fashioned on bipolar products. The bifacial group is well represented including two axes on green stone. The abundant obsidian assemblage comprises more than 400 artefacts including cores, waste and tools. The small finds also include ground-stone tools, several figurines and a collection of beads and stone bracelets.

The basis for dating Layer VI to the EPPNB includes the material culture remains together with a large series of ${ }^{14} \mathrm{C}$ dates, which range between 8500-8000 cal. BC (see below).

\section{RADIOCARBON DATING LAYER VI [E.B. and O.B.-Y.]}

Radiocarbon dating of Motza was performed on charcoal and bone samples that were collected during the 2002-2003 excavation. A total of 26 samples ( 6 bones, 2 humic acids, 18 charcoals) were dated with ${ }^{14} \mathrm{C}$ using the Accelerator Mass Spectrometry technique. Table 1 presents the samples relating to Layer VI, i.e. the EPPNB level, the samples being collected from different locations within the excavated area. The range of most dates fall within the Levantine EPPNB. One exception is sample TO-11710, which is significantly older and falls in the PPNA range.

During the 2003 excavation a new dating strategy was adopted at the Weizmann Institute radiocarbon dating laboratory and systematically applied to the samples collected for dating (see tab. 1 samples *RTT). The new approach was intended to assure the highest quality, regarding precision and accuracy, of the radiocarbon dating. For this purpose it was necessary to select the samples from secure archaeological contexts, prove the purity of the material to be dated, ${ }^{14}$ and determine the analytical accuracy and precision of the method. The strategy adopted for the Motza samples, in order to insure the highest accuracy and precision, has been presented elsewhere. ${ }^{15}$ Samples were first selected on the basis of their importance to the archaeological context and stratigraphy. Since the measurement was performed using the Accelerator Mass Spectrometry

14. VAN KLINKEN, 1999.

15. YIZHAQ et al., 2005. 


\begin{tabular}{|c|c|c|c|c|c|c|c|}
\hline Lab code & \# & Type & $\begin{array}{c}{ }^{14} \mathrm{C} \text { age } \\
\pm 1 \sigma \text { year BP } \\
\end{array}$ & $\begin{array}{c}\text { Calibrated age } \\
\pm 1 \sigma \text { year BP }\end{array}$ & $\begin{array}{c}\text { Calibrated age } \\
\pm 2 \sigma \text { year BP } \\
\end{array}$ & Collection Site & Sample ID \\
\hline TO & 11710 & charcoal & $9870 \pm 90$ & $\begin{array}{c}11,600(1.8 \%) 11,570 \\
11,410(66.4 \%) \\
11,180\end{array}$ & $11,750(95.4 \%) 11,100$ & PPNA? & 41286 \\
\hline${ }^{*} \mathrm{RTT}$ & $\begin{array}{c}4750.1 \\
4750.2 \\
4750.3 \\
\text { average } \\
\end{array}$ & bone & $\begin{array}{l}9350 \pm 50 \\
9290 \pm 50 \\
9290 \pm 50 \\
9310 \pm 30 \\
\end{array}$ & 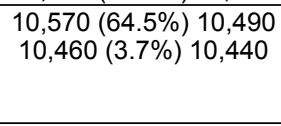 & $10,590(95.4 \%) 10,410$ & $\begin{array}{l}\text { Sq. N18d, z 587.97, } \\
\text { L. } 4071 \text {, B. } 41303\end{array}$ & * \\
\hline${ }^{*} \mathrm{RTT}$ & $\begin{array}{c}4752.1 \\
4752.2 \\
4752.3 \\
4752.4 \\
\text { average } \\
\end{array}$ & bone & $\begin{array}{l}9230 \pm 50 \\
9200 \pm 50 \\
9200 \pm 50 \\
9210 \pm 50 \\
9210 \pm 25\end{array}$ & $10,420(68.2 \%) 10,290$ & $\begin{array}{c}10,490(8.3 \%) 10,450 \\
10,440(87.1 \%) \\
10,260\end{array}$ & $\begin{array}{l}\text { Sq. N18a, z 588.35, } \\
\text { L. } 4076 \text {, B. } 41371\end{array}$ & * \\
\hline${ }^{*} \mathrm{RTT}$ & \begin{tabular}{c|}
4867.1 \\
4867.2 \\
4867.3 \\
4867.4 \\
average \\
\end{tabular} & charcoal & $\begin{array}{c}9160 \pm 125 \\
9200 \pm 80 \\
9220 \pm 80 \\
9140 \pm 115 \\
9200 \pm 45 \\
\end{array}$ & $10,420(68.2 \%) 10,260$ & $10,500(95.4 \%) 10,240$ & East wall & 246 \\
\hline TO & 11712 & charcoal & $9170 \pm 80$ & $10,420(68.2 \%) 10,240$ & $10,550(95.4 \%) 10,200$ & EPPNB & 50779 \\
\hline${ }^{*} \mathrm{RTT}$ & $\begin{array}{c}4866.1 \\
4866.2 \\
4866.3 \\
\text { average } \\
\end{array}$ & charcoal & $\begin{array}{l}9215 \pm 55 \\
9190 \pm 55 \\
9035 \pm 55 \\
9150 \pm 35\end{array}$ & $\begin{array}{l}10,380(17.4 \%) \\
10,300(50.8 \%) \\
10,240\end{array}$ & 10,410 (95.4\%) 10,230 & East wall & 209 \\
\hline${ }^{*} \mathrm{RTT}$ & $\begin{array}{c}4749.1 \\
4749.2 \\
4749.3 \\
\text { average } \\
\end{array}$ & bone & $\begin{array}{l}9130 \pm 50 \\
9155 \pm 50 \\
9100 \pm 50 \\
9130 \pm 30 \\
\end{array}$ & $10,290(68.2 \%) 10,230$ & $10,390(95.4 \%) 10,220$ & $\begin{array}{l}\text { Sq. N19a, z } 587.91 \\
\text { L. } 4070 \text {, B. } 41324\end{array}$ & \\
\hline${ }^{*} \mathrm{RTT}$ & $\begin{array}{c}4751.1 \\
4751.2 \\
4751.3 \\
\text { average }\end{array}$ & bone & $\begin{array}{l}9080 \pm 50 \\
9090 \pm 50 \\
9100 \pm 50 \\
9100 \pm 30\end{array}$ & $10,250(68.2 \%) 10,220$ & $10,280(95.4 \%) 10,195$ & $\begin{array}{l}\text { Sq. N18d, z 588.18, } \\
\text { L. 4062, B. } 41204\end{array}$ & * \\
\hline${ }^{*} \mathrm{RTT}$ & $\begin{array}{c}4865.1 \\
4865.2 \\
4865.3 \\
4865.4 \\
\text { average } \\
\end{array}$ & charcoal & $\begin{array}{l}9030 \pm 55 \\
9120 \pm 55 \\
9085 \pm 55 \\
9100 \pm 75 \\
9080 \pm 30 \\
\end{array}$ & $10,250(68.2 \%) 10,220$ & 10,265 (95.4\%) 10,195 & $\mathrm{N} 19 \mathrm{a}$ & 115 \\
\hline TO & 11711 & charcoal & $9050 \pm 80$ & 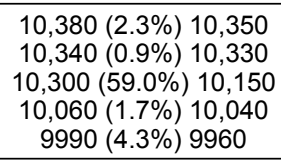 & $10,500(95.4 \%) 9900$ & EPPNB & 50761 \\
\hline${ }^{*} \mathrm{RTT}$ & $\begin{array}{c}4753.1 \\
4753.2 \\
4753.3 \\
\text { average }\end{array}$ & bone & $\begin{array}{l}8990 \pm 50 \\
8990 \pm 70 \\
9000 \pm 55 \\
8995 \pm 35\end{array}$ & 10,225 (68.2\%) 10,175 & 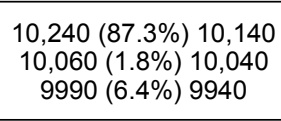 & $\begin{array}{l}\text { Sq. O19c, z } 589.01 \text {, } \\
\text { x 625, y } 440\end{array}$ & $\begin{array}{l}\text { human } \\
\text { female }\end{array}$ \\
\hline RTT & 4577 & charcoal & $8965 \pm 45$ & $\begin{array}{c}10,230(42.9 \%) 10,130 \\
10,070(6.5 \%) 10,040 \\
10,030(2.7 \%) 10,010 \\
9990(16.2 \%) 9940 \\
\end{array}$ & $\begin{array}{c}10,230(51.9 \%) 10,110 \\
10,090(43.5 \%) 9910\end{array}$ & $\begin{array}{c}\text { 3612, sq. B upper, } \\
\text { L } 2082\end{array}$ & \#37 \\
\hline RTT & 4579 & charcoal & $8890 \pm 45$ & $\begin{array}{c}10,160(14.7 \%) 10,110 \\
10,090(53.5 \%) 9920\end{array}$ & $\begin{array}{c}10,190(91.4 \%) 9860 \\
9850(4.0 \%) 9780 \\
\end{array}$ & $\begin{array}{c}\text { 3612, sq. B upper, } \\
\text { L } 2138\end{array}$ & $\# 45$ \\
\hline${ }^{*} \mathrm{RTT}$ & $\begin{array}{c}4867.1 \\
4867.2 \\
4867.3 \\
4867.4 \\
\text { average } \\
\end{array}$ & charcoal & $\begin{array}{c}9160 \pm 125 \\
9200 \pm 80 \\
9220 \pm 80 \\
9140 \pm 115 \\
9200 \pm 45 \\
\end{array}$ & $10,420(68.2 \%) 10,260$ & $10,500(95.4 \%) 10,240$ & East wall & 246 \\
\hline${ }^{*} \mathrm{RTT}$ & 4869.1 & humic acids & $9040 \pm 40$ & $10,240(68.2 \%) 10,195$ & 10,255 (95.4\%) 10,170 & $\begin{array}{c}\text { humic from } \\
115 \\
\end{array}$ & \\
\hline${ }^{*} \mathrm{RTT}$ & 4882.1 & humic acids & $9030 \pm 50$ & $10,240(68.2 \%) 10,180$ & $\begin{array}{c}10,270(89.1 \%) 10,130 \\
10,070(1.6 \%) 10,040 \\
10,000(4.8 \%) 9930 \\
\end{array}$ & $\begin{array}{l}\text { humic acids from soil } \\
\text { near sample } 115\end{array}$ & \\
\hline
\end{tabular}

Samples in the table are ordered according to radiocarbon age. Laboratory code TO relates to the Toronto Isotrace Laboratory (Toronto, Canada), RTT to Weizmann Institute Radiocarbon dating laboratory (Rehovot, Israel). Samples coded *RTT relate to those measured within the framework of YIZHAQ, 2004 and published in YIZHAQ et al., 2005. Only these samples were submitted to the pre-screening methodology.

${ }^{14} \mathrm{C}$ are reported in conventional radiocarbon years according to STUIVER and POLACH, 1977 with one standard deviation ( $\pm 1 \sigma$ ). Calibrated ages are given in columns 5 and 6 for $\pm 1 \sigma$ and $\pm 2 \sigma$ respectively. If more than one calibrated range is possible the relative probability is given between the limit of the range. Calibrated ages have been determined using the OxCal 3.10 (2005) of BRONK-RAMSEY (1995 and 2001) using the INTCAL04 calibration curve (REIMER et al., 2003). Five samples were measured more than once (RTT 4750, 4751, 4865, 4866, 4867). The calibrated age is given for the weighted average of the multiple measurements.

Tab. 1: ${ }^{14}$ C dates from Layer VI 
Atmospheric data from Reimer et al. (2004); OxCal v3.10 BRonk RAMSEY (2005); cub r:5 sd:12 prob usp[chron]

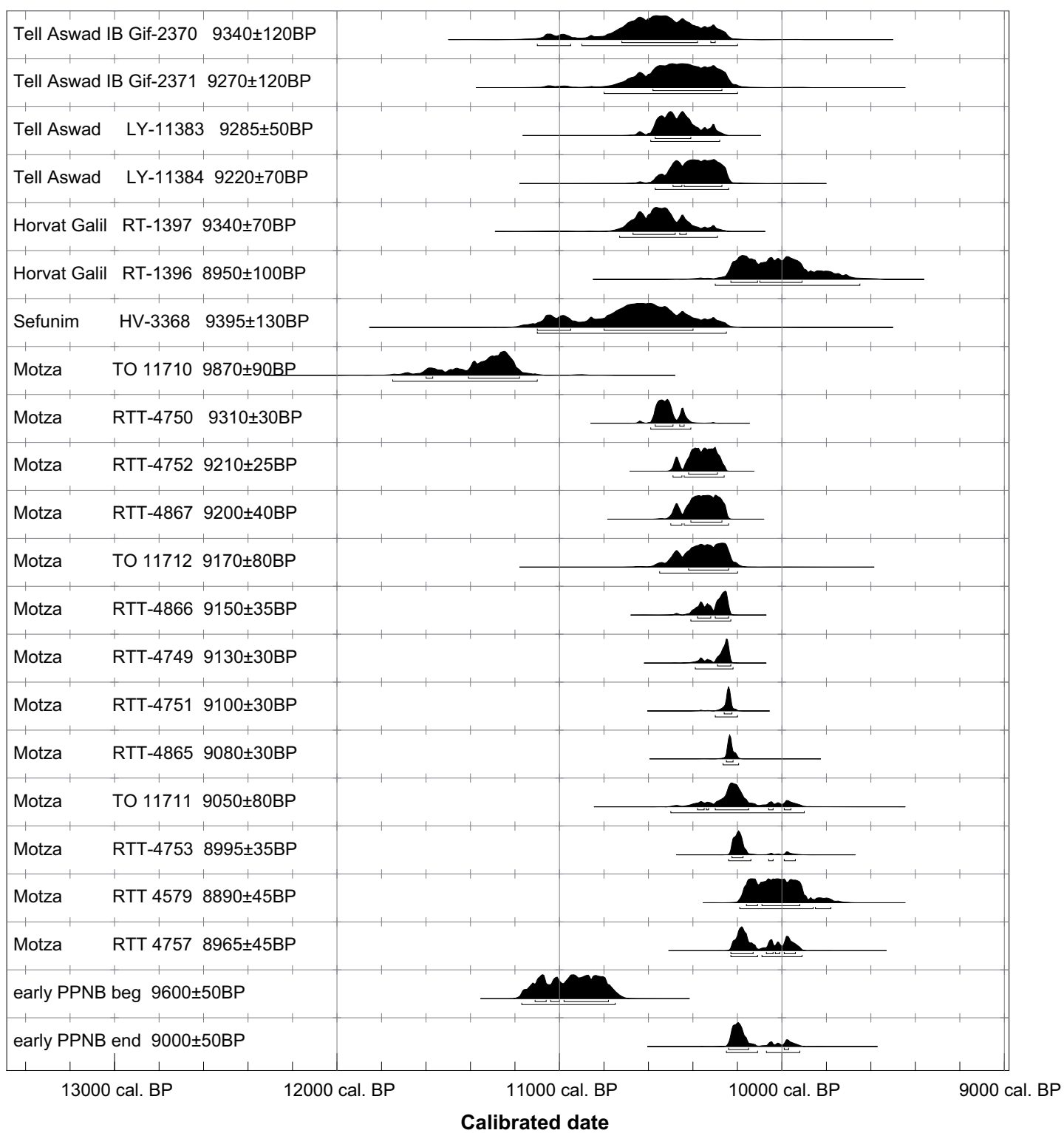

Fig. 7: Probability distribution of the calibrated radiocarbon ranges. Samples measured in this study are shown in addition to early PPNB samples from other sites in the central southern Levant, i.e. Tell Aswad (STORDEUR, 2003), Horvat Galil (GOPHER, 1989a) and Sefunim (RONEN, 1988).

technique, the size of the sample was not a parameter for selection. In the laboratory the strategy followed was to characterize the material before and after pre-treatment and select the sample based on the best quality of the material. The different techniques for pre-screening of samples included Fourier
Transform Infrared analysis, Raman Spectroscopy and amino acid analysis depending on the type of material. ${ }^{16}$ With these techniques the quality of the charcoal and the bone before

16. YIZHAQ et al., 2005. 
and after pre-treatment was analyzed and only samples that provided spectra of pure charcoal and collagen were later selected for radiocarbon dating. A total of 30 bones and 9 charcoal samples were pre-screened from the EPPNB Layer VI at Motza.

For both type of samples analyzed, charcoal and bone, one possible source of contamination is the humic substances present in the sediments. These substances, which originate from the degradation of organic material, are mobile in sediments with water and get absorbed in the charcoal or bone samples. The Acid-Base-Acid protocol used for radiocarbon samples pre-treatment removes such humic substances. Raman spectroscopy analysis was applied following the removal of such substances ${ }^{17}$ during the pretreatment. We also measured the radiocarbon content of humic substances RTT 4869.1 derived from charcoal sample RTT 4865, and humic substances RTT 4882.1 from the sediments related to sample RTT 4865. In both cases the ages are similar to the age of charcoal RTT 4865. These results suggest that the origin of the humic substances is from material contemporary with the charcoal sample. The series of results obtained from Motza Layer VI are very close and both types of material (bone and charcoal) give the same range. The pre-screening method applied to *RTT samples and the close range of multiple measurements for the same sample assure high accuracy and precision for this set of measurements. In figure 7 the probability distribution of the calibrated age for this set (except for the two humic acid samples) is shown with the radiocarbon age from other middle southern Levant sites. The uncertainty associated with the ${ }^{14} \mathrm{C}$ age from other sites such as Tell Aswad ${ }^{18}$, Horvat Galil ${ }^{19}$ and Sefunim ${ }^{20}$ compared to the new set of Motza dates, result in a large calibrated interval. At this point it is not possible to determine any sequence between different sites. The last two distributions are the simulated calibrated ages for the generally accepted limit of the beginning and end of the EPPNB. All the measurements fall within this limit.

17. ALON et al., 2002.

18. STORDEUR, 2003.

19. GOPHER, 1989a.

20. RONEN, 1988.

\section{THE EPPNB FLINT ASSEMBLAGE} [O.B. and O.M.]

This preliminary report describes a randomly selected sample from the Layer VI lithic assemblage. It derives from secure stratigraphic contexts in both sectors and comprises 9,152 artefacts, representing $c a 10 \%$ of the entire assemblage. Since the major emphasis in this preliminary report is chronological, special attention herein focuses on the formal tools, i.e. projectile points, sickle blades and bifacials, which are considered reliable diagnostic means for relative dating. ${ }^{21}$ In addition to the sampled assemblage, a further 202 projectile points and 30 bifacial tools were also analyzed, all deriving from clean contexts in Layer VI. Another chronological marker for the initiation of the PPNB in the southern Levant is considered to include the presence of the bidirectional blade technology. ${ }^{22}$ Accordingly, additional information regarding the reduction sequence of a bidirectional blades cache, which has been described elsewhere, is summarized. ${ }^{23}$

\section{RAW MATERIAL}

Two types of fine-grained flint from Cenomanian/Quaternary formations were used for the lithic industry at Motza. The first is a local Judean flint group of various colours, which is also characteristic at the nearby MPPNB site of Abu Gosh. ${ }^{24}$ This flint usually occurs as small nodules that were exploited for flake and bladelet productions. Larger, light grey nodules were favoured for bifacials, especially the tranchet types. The second type comprises high quality, lustrous flint ranging from dark purple, through brown and reddish, to pink. In Layer VI at Motza this raw material was used exclusively for the production of bidirectional blades; it resembles the Wadi Huweijir outcrop that was identified as the main flint source at MPPNB and LPPNB Ain Ghazal. ${ }^{25}$ Although the outcrops of this flint group at Motza remain to be located, we believe that it will be traced in local exposures of the same formation.

\footnotetext{
21. e.g. BARKAI, 2005; GOPHER, 1994.

22. BAR-YOSEF, 2001; CAUVIN, 2000; KUIJT and GORING-MORRIS,

23. KHALAILY et al., in press.

24. KHALAILY and MARDER, 2003; LECHEVALLIER, 1978.

25. QUINTERO, 1996.
} 2002. 

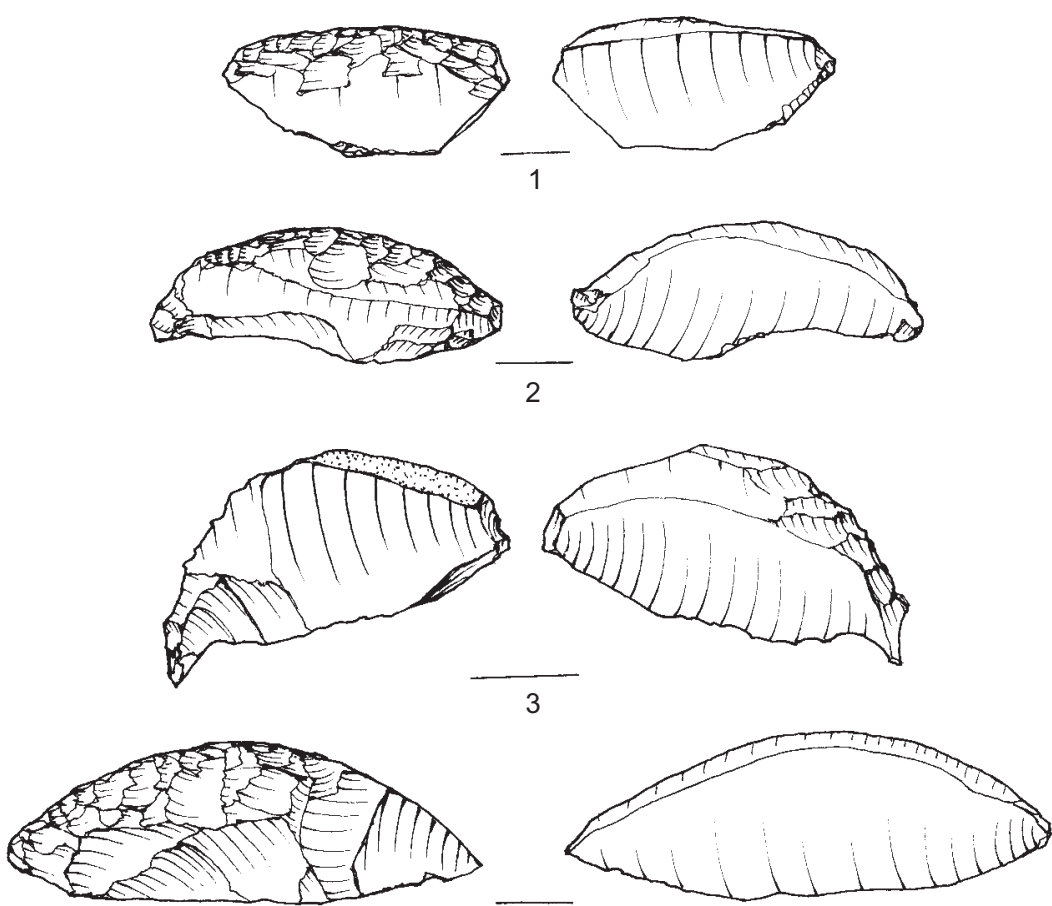

4
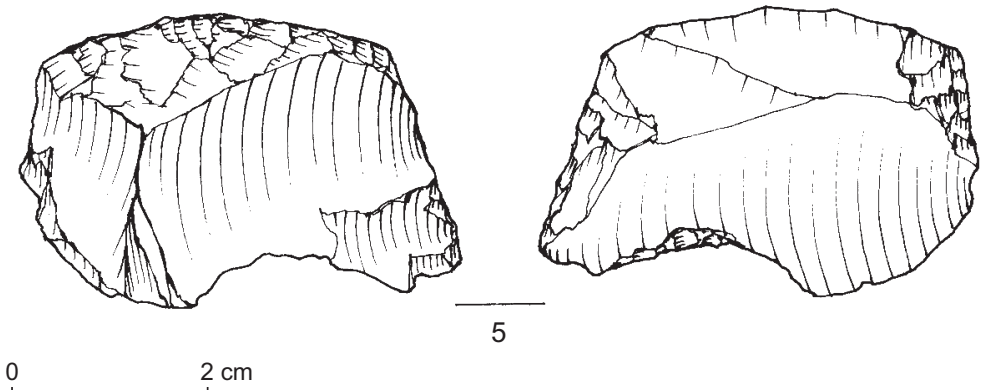

Fig. 8: Bifacial waste. 1-4, transversal spalls; 5, side spall.

\section{DEBITAGE}

The flint assemblage of Layer VI includes at least four technologies: ad hoc flake, bidirectional naviform blade, bladelet and bifacial tool reduction sequences. All four can be identified in the debitage, tools and core categories. Flakes are the most common debitage group type comprising $\mathrm{ca} 60 \%$ (tab. 2). The second largest group is the blades, most being non-targeted byproducts $(\mathrm{n}=542)$, while the bidirectional items comprise only $7 \%$. The flake/blade ratio is extremely pronounced (3.51:1), thus pointing to the dominance of the ad hoc flake technology. On the other hand the flake/blade ratio is much lower (1.18:1) amongst the tools, indicating the marked preference for blade blanks. Burin spalls are quite numerous $(n=133)$, corresponding to the high proportions of burins in the tool category (tab. 4). Interestingly, the majority of the spalls were removed from blades, whereas the burins themselves were mainly made on flakes. It seems likely that, in addition to burin production, the spalls also represent blade sectioning for further modification.

The bifacial waste products in the assemblages are mainly tranchet spalls $(\mathrm{n}=58)$, although various thinning flakes were also noted $(n=13)$. The latter are extremely thin items bearing radial, dorsal scar patterns. The tranchet spalls are frequent when compared to the tranchet axes, showing a ratio of 58:1 (fig. 8). It seems that the main cause for this discrepancy is 

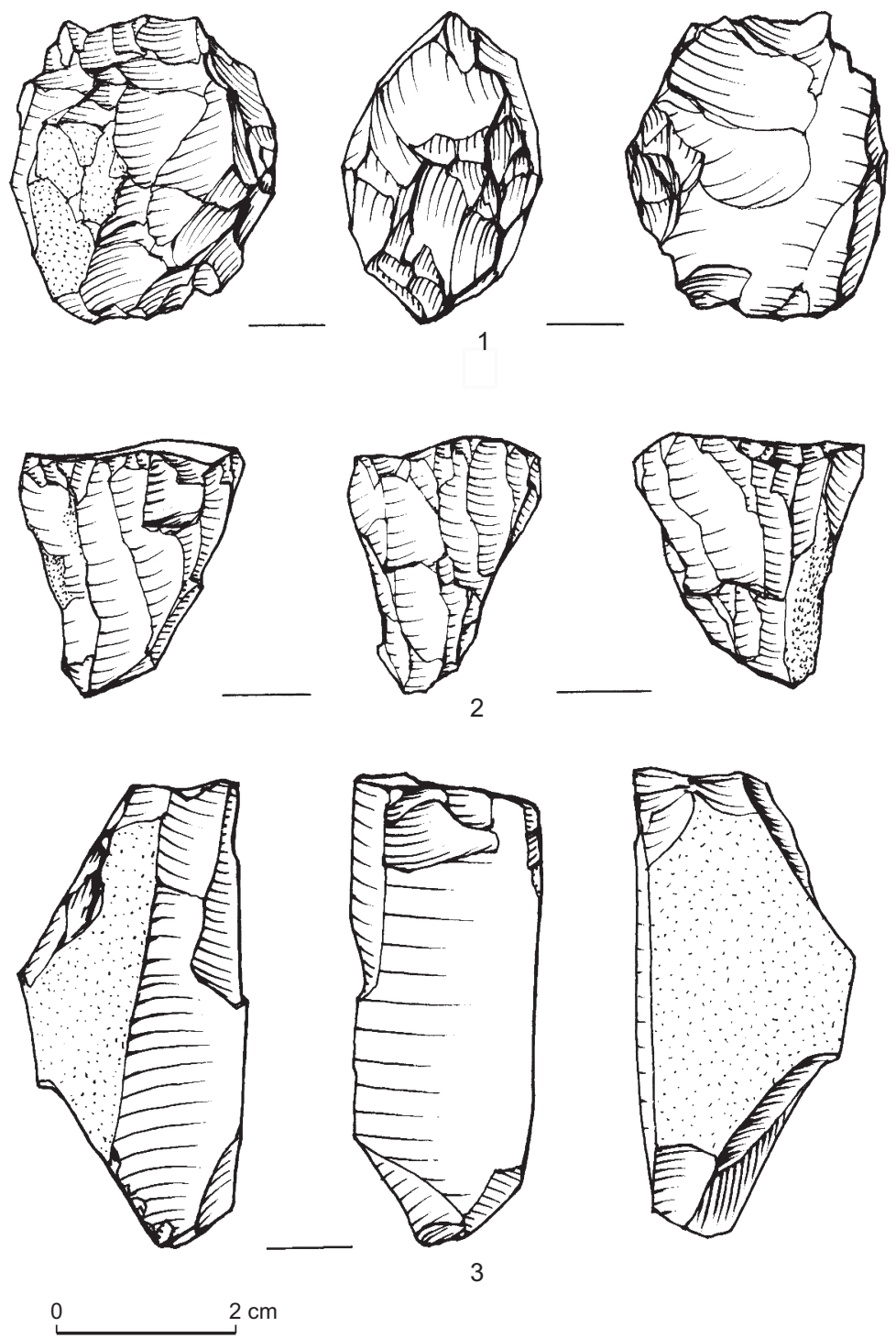

3

Fig. 9: Cores. 1-2, one striking platforms; 3, amorphous core.

that the tranchet axes were repeatedly re-sharpened. If so one would expect short tranchet axes, as is indeed the case at Motza (tab. 5). ${ }^{26}$

\section{CORES}

Cores are not well represented in the assemblage $(0.7 \%)$ and reflect mainly the ad hoc flake and bladelet technolo-

26. BARKAI, 2005. gies (tab. 3). These were made on the local fine-grained flint (group 1). The single bidirectional blade core is made on the high quality lustrous pink flint (group 2).

All core types display intensive utilization since almost all are exhausted (fig. 9). Similar observations were noted at Abu Gosh. ${ }^{27}$ Since neither Motza nor Abu Gosh are located directly on or adjacent to flint outcrops such a pattern of intensive utilization is to be expected.

27. KHALAILY and MARDER, 2003. 


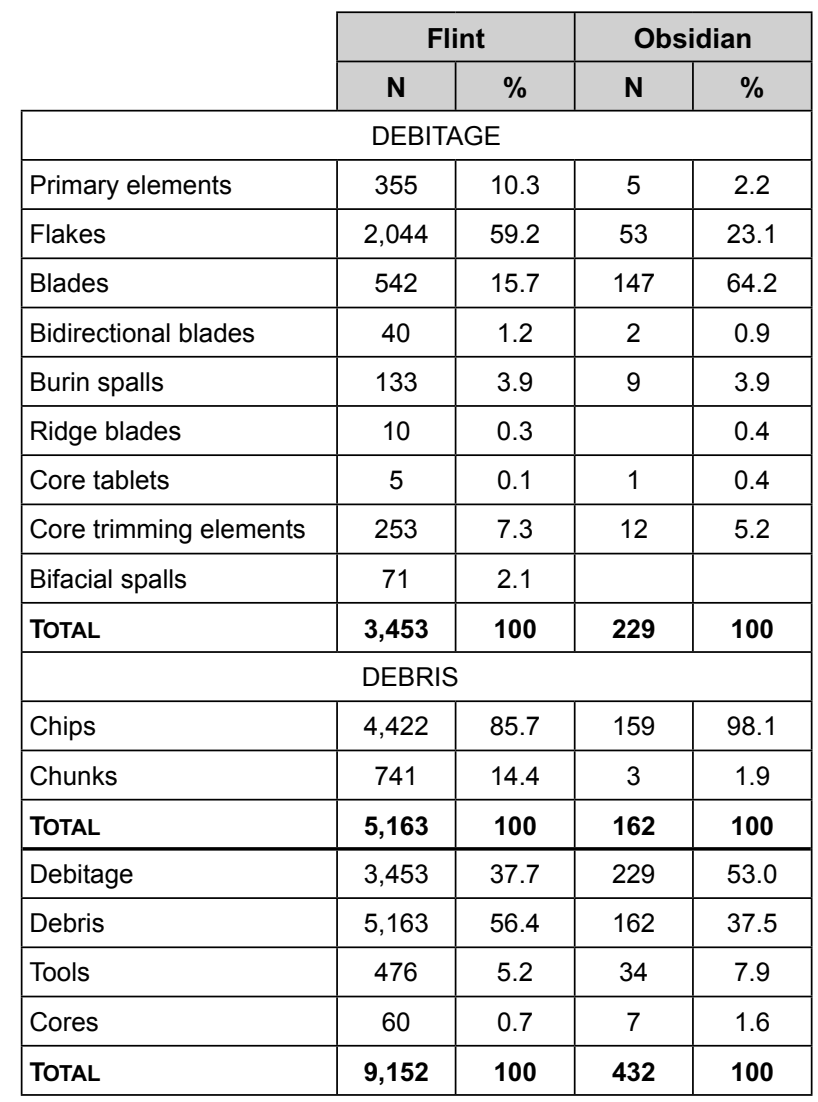

\begin{tabular}{|l|c|c|c|c|}
\hline Type & N & \% & N & \% \\
\hline Projectile points & 35 & 7.4 & 10 & 30.3 \\
\hline Perforators & 17 & 3.6 & 1 & 3.0 \\
\hline Sickle blades & 34 & 8.0 & 2 & 6.1 \\
\hline Retouched blades & 84 & 17.6 & 15 & 45.5 \\
\hline Retouched flakes & 93 & 19.5 & 2 & 6.1 \\
\hline Scrapers & 22 & 4.6 & - & \\
\hline Burins & 87 & 18.3 & - & \\
\hline Notches/Denticulates & 45 & 9.5 & - & \\
\hline Truncations & 7 & 1.5 & - & \\
\hline Microliths & 4 & 0.8 & - & \\
\hline Knives & 2 & 0.4 & - & \\
\hline Multiple tools & 5 & 1.1 & - & \\
\hline Bifacials & 16 & 3.4 & - & \\
\hline Varia & 19 & 4.0 & 3 & 9.1 \\
\hline Hammerstones & 2 & 0.4 & - & \\
\hline ToTAL & $\mathbf{4 7 2}$ & $\mathbf{1 0 0}$ & $\mathbf{3 3}$ & $\mathbf{1 0 0 . 1}$ \\
\hline
\end{tabular}

Tab. 4: EPPNB tool counts and frequencies of the flint and obsidian assemblages in Layer VI at Motza.

Tab. 2: General counts and frequencies for the flint and obsidian assemblages from Layer VI at Motza.

\begin{tabular}{|l|c|c|}
\hline Cores & N & \% \\
\hline Flake & 3 & 5.0 \\
\hline Blade & 4 & 6.7 \\
\hline Bladelet & 18 & 30.0 \\
\hline Bidirectional blade & 1 & 1.7 \\
\hline Flake/bladelet & 4 & 6.7 \\
\hline Small flakes & 11 & 18.3 \\
\hline Fragments & 19 & 31.7 \\
\hline ToTAL & $\mathbf{6 0}$ & $\mathbf{1 0 0}$ \\
\hline
\end{tabular}

Tab. 3: Core frequencies in Layer VI at Motza.

\begin{tabular}{|c|c|c|c|c|c|}
\cline { 2 - 6 } \multicolumn{2}{c|}{} & $\begin{array}{c}\text { Helwan } \\
\text { on flake }\end{array}$ & $\begin{array}{c}\text { Helwan } \\
\text { on blade }\end{array}$ & $\begin{array}{c}\text { Jericho } \\
\text { on flake }\end{array}$ & $\begin{array}{c}\text { Jericho } \\
\text { on blade }\end{array}$ \\
\hline \multirow{4}{*}{ Length } & $\mathrm{N}$ & 23 & 10 & 18 & 12 \\
\cline { 2 - 6 } & Mean & 26.62 & 40.32 & 30.79 & 45.96 \\
\cline { 2 - 6 } & sd & 3.55 & 14.36 & 4.65 & 9.17 \\
\cline { 2 - 6 } & Minimum & 20.53 & 27.13 & 21.37 & 29.84 \\
\cline { 2 - 6 } & Maximum & 37.35 & 75.87 & 37.79 & 62.56 \\
\hline Width & $\mathrm{N}$ & 37 & 18 & 21 & 26 \\
\cline { 2 - 6 } & Mean & 14.72 & 12.76 & 15.62 & 16.11 \\
\cline { 2 - 6 } & sd & 2.25 & 1.73 & 2.50 & 2.69 \\
\cline { 2 - 6 } & Minimum & 10.78 & 9.98 & 9.99 & 10.36 \\
\cline { 2 - 6 } & Maximum & 20.44 & 16.73 & 19.76 & 21.95 \\
\hline \multirow{5}{*}{ Thickness } & $\mathrm{N}$ & 39 & 18 & 22 & 26 \\
\cline { 2 - 6 } & Mean & 3.35 & 3.72 & 3.65 & 4.98 \\
\cline { 2 - 6 } & sd & 0.67 & 0.72 & 1.32 & 1.13 \\
\cline { 2 - 6 } & Minimum & 1.94 & 2.42 & 2.21 & 3.05 \\
\hline & Maximum & 4.98 & 5.06 & 7.49 & 7.02 \\
\hline \multirow{5}{*}{ W/L ratio } & $\mathbf{1 . 9 : 1}$ & $\mathbf{1 . 3 : 1}$ & $\mathbf{2 : 1}$ & $\mathbf{3 : 1}$ \\
\hline
\end{tabular}

Tab. 5: Helwan and Jericho point variants in the Layer VI Motza sample. 


\section{TOOLS}

The tools in the assemblage are divided into formal and non-formal types (tab. 4). The formal types include projectiles, sickle blades and bifacials. Within the non-formal tools retouched flakes ( $c a 20 \%, \mathrm{n}=93$ ) are the dominant type. The second largest group is the retouched blades $(n=84)$. Most are made on various types of blade, with only $25 \%$ being shaped on bidirectional blanks. Other groups demonstrating a preference for flake blanks are the burins $(n=87)$, notches and denticulates $(n=45)$, scrapers $(n=22)$ and perforators $(n=17)$.

The only other tool class that shows a clear preference for bidirectional blades is the sickle blades (fig. 10). This group comprises $8 \%$ of the tools (tab. 4), which is relatively low for a residential PPNB site within the Mediterranean woodland zone. ${ }^{28}$ Most of the sickle blades are fragmented and burnt. Although this prevented detailed attribute analysis, some morphological observations such as scar directions and type of retouch could be recorded. Half of the sickles are plain and display no retouch, while the remainder is shaped by fine-ventral retouch; this retouch becomes characteristic in the MPPNB, e.g. Munhata, where at least $75 \%$ of the sickles display fineventral retouch. ${ }^{29}$

The projectile points comprise $7.4 \%$ of the tool assemblage (tab. 4). As mentioned above their detailed analysis includes an additional 202 items. Typologically, the majority are Helwan and Jericho points, which were made by using two blank forms by distinct production technologies: flakes and bidirectional blades (fig. 11).

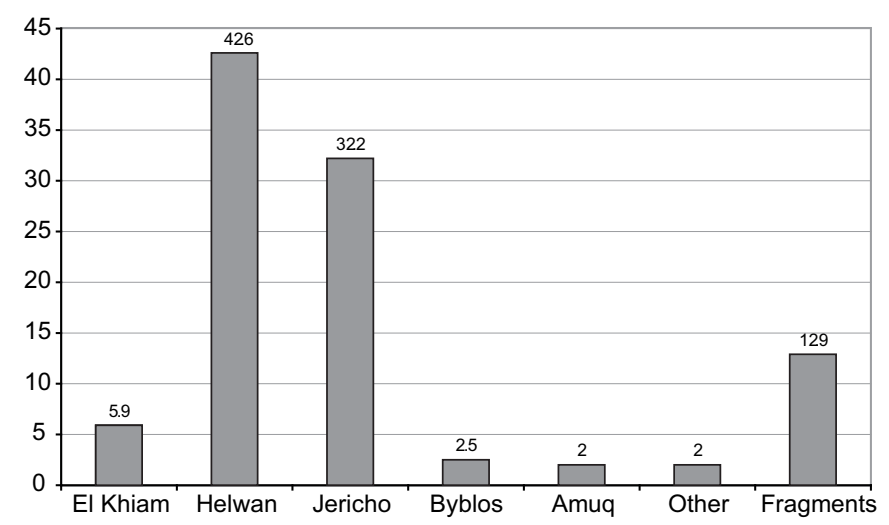

Fig. 11: Projectile points frequency in the Layer VI Motza sample $(N=194)$.

28. At Abu Gosh sickle blades comprise $17.2 \%$ of the tools (KHALAILY and MARDER, 2003: 28).

29. GOPHER, 1989b: 44.
The Helwan points $(n=86)$ comprise two sub-types that correspond to the blanks on which they were made. The most abundant, fashioned on flakes, are short triangular points that resemble a clover leaf (fig. 12: 1-6). These short, stubby points were intensively retouched on both faces and their width/ length ratio is 1:1.8 (tab. 5). Interestingly this sub-type is also the dominant one at Nahal Lavan 109 in the western Negev. ${ }^{30}$

The other sub-type is an elongated Helwan point that was fashioned on a bidirectional blade (fig. 12: 8). The width/length ratio is 1:3.1. This bears comparisons to the northern variant of the Helwan point (also termed 'Aswad point'), found at Tell Aswad. ${ }^{31}$

The Jericho points $(n=65)$ are broadly comparable, with one sub-type being elongated on bidirectional blades (fig. 13). Most of this sub-type display pronounced wings, and relatively short (W/L ratio 1:2.7) and thick proportions (tab. 5). This may reflect the fact that one third are made on recycled sickle blades.

The second Jericho point sub-type is small and broad, being made mainly on flake blanks. This sub-type is also present in other PPNB assemblages, although it is occasionally classified as a Pottery Neolithic type. ${ }^{32}$ Their general shape conforms to Haparsa points, but they are larger and display less pressure retouch. The $\mathrm{L} / \mathrm{W}$ ratio within this sub-type is 1:2 (tab. 5).

The Khiam point $(\mathrm{n}=12)$ is the third-most frequent type. They were shaped by bilateral notches located at the extreme proximal end, i.e. close to the base (fig. 12: 10-14). Most are made on small blades and bladelets (only two being on bidirectional blades). They are short and stubby $(28.7 \mathrm{~mm}$ long, $12.5 \mathrm{~mm}$ wide, and $2.7 \mathrm{~mm}$ thick) compared to 'normative' PPNA types as found at Jericho Nahal Oren, Netiv Hagdud and other sites. ${ }^{33}$ Some have flat bases fashioned by Couze-type retouch, typical of the PPNA..$^{34}$ One item in this group can be classified as a Salibiya point since it lacks bilateral notches.

Abu Gosh retouch, which is a hallmark of the south Levantine MPPNB assemblages in the Mediterranean woodland zone, is completely absent at Motza. Impact fractures appear on $20 \%$ of the projectiles.

The bifacials are dominated by two types: the axe and the chisel. Local fine-grained flint (group A) was the main raw material used (fig. 14). The majority ( $c a 70 \%$ ) of both types display tranchet working ends. Most were carefully fashioned. With one exception none of the bifacials were polished.

30. BURIAN et al., 1999; GOPHER, 1994.

31. CAUVIN, 1995; STORDEUR, 2003.

32. KHALAILY and MARDER, 2003: 42; GOPHER, 1994: 55.

33. GOPHER, 1994: appendix I; NADEL, 1997: tab. 4.14.

34. BAR-YOSEF and GOPHER, 1997. 

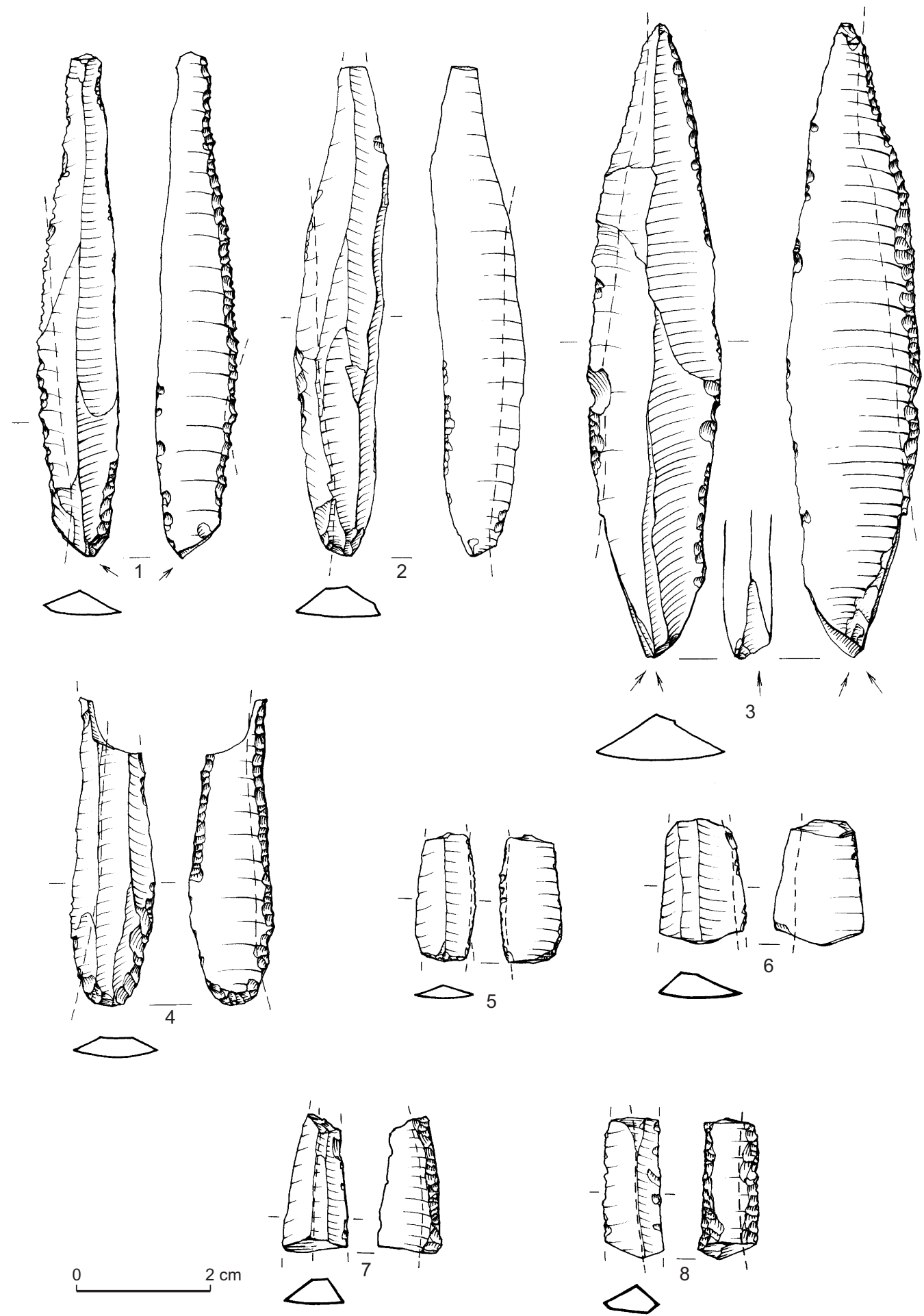

Fig. 10: Sickle blades. 1, 3-4, 6, 8-9, fine ventral retouched; 2, 7, plain sickle blades; 5, bifacially retouched. 

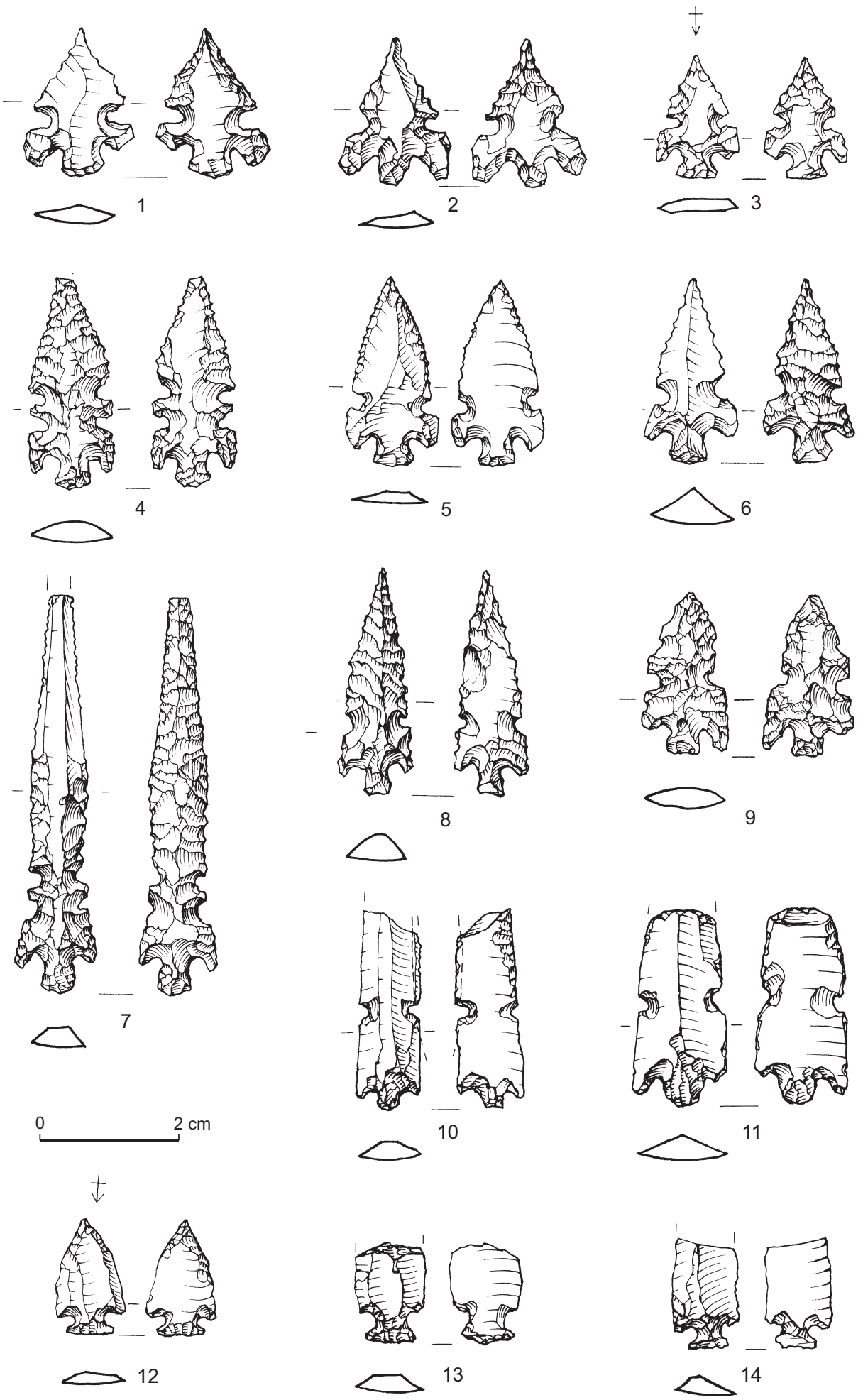

Fig. 12: Projectile points. 1-11, Helwan points; 12-14, Khiam points. 

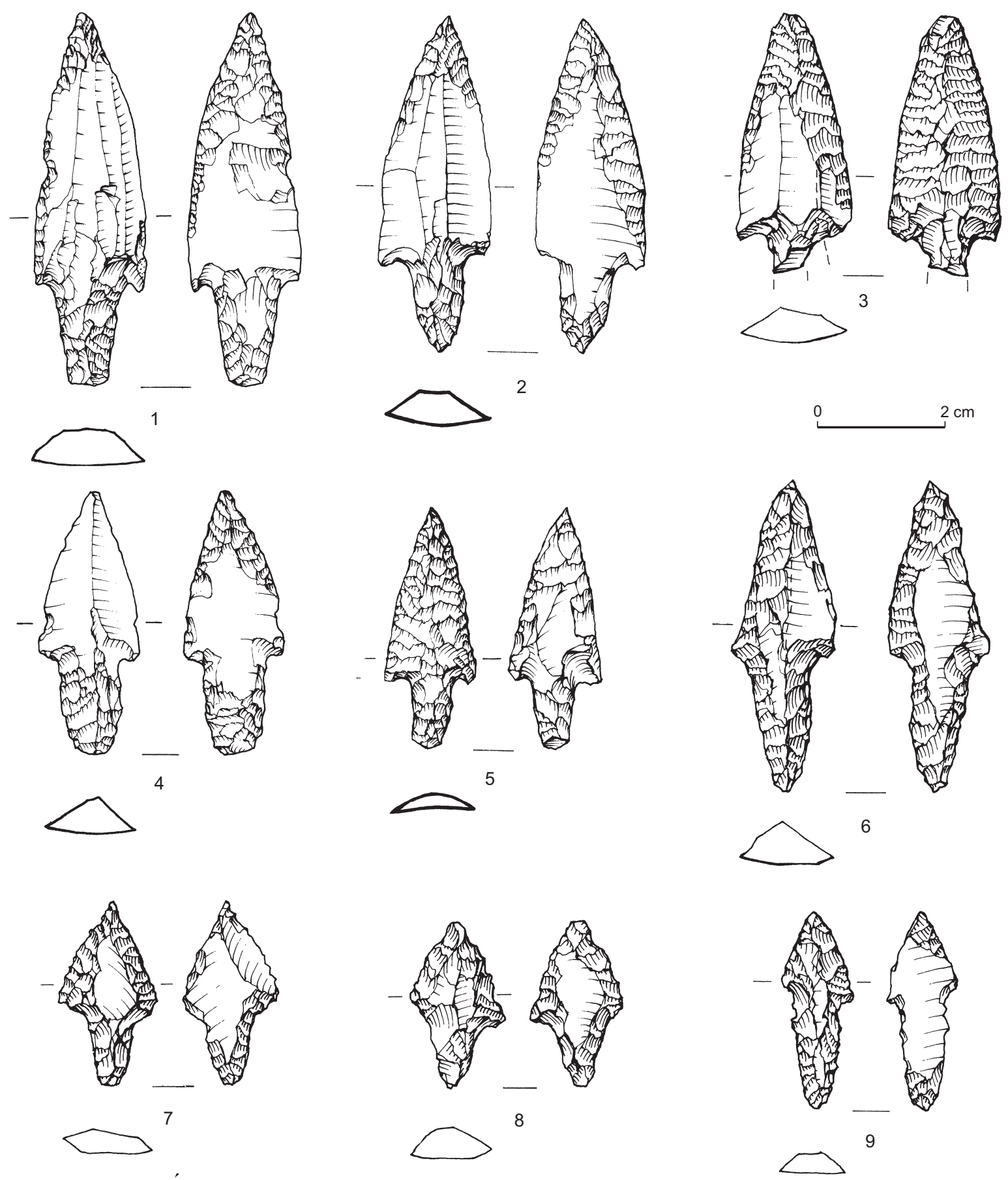

Fig. 13: Projectile points. 1-6, Jericho points; 7-9, small intermediate points. 

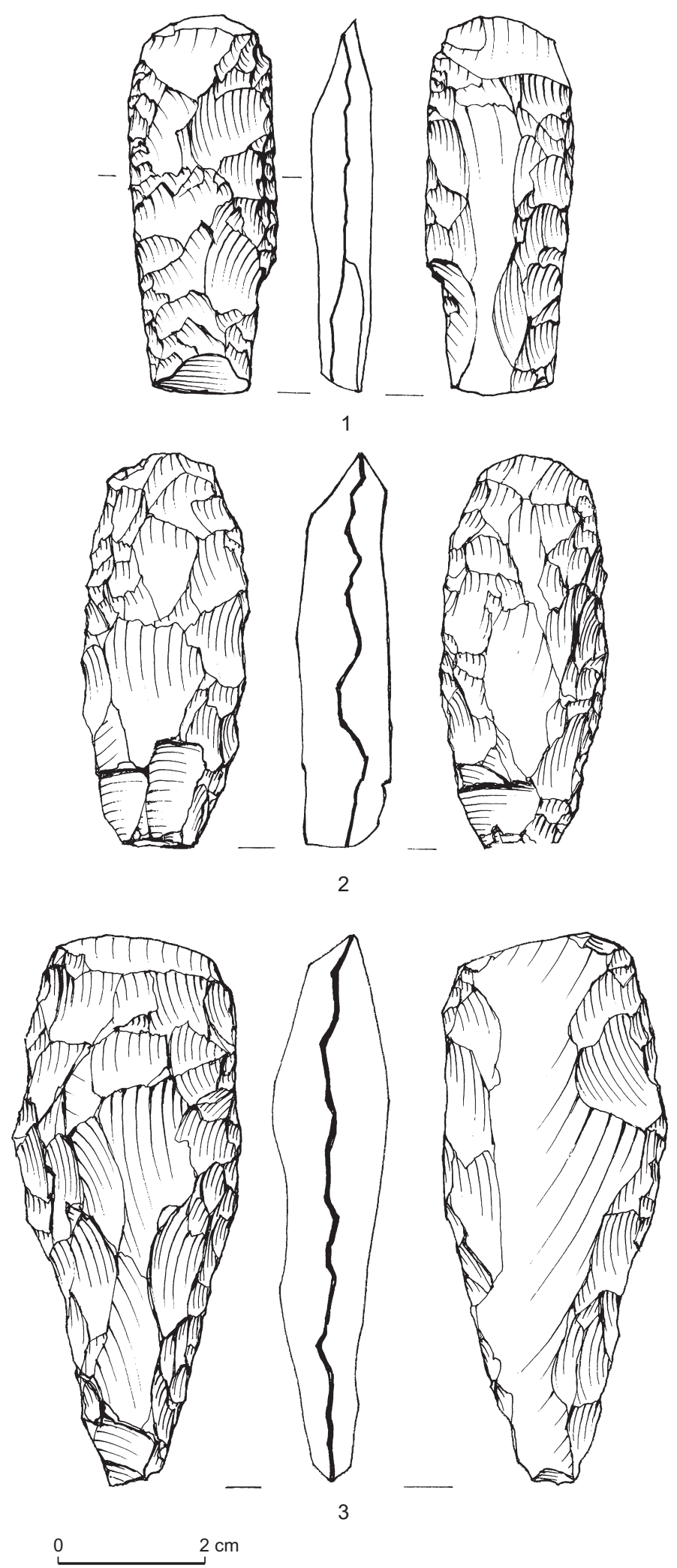

Fig. 14: Bifacials. 1-3, axes. 
The tranchet axes are relatively small and light, as reflected by their mean dimensions of $61.6 \times 29.2 \mathrm{~mm}$, and their weight averages 33.2 grams. The non-tranchet axes are of similar dimensions: $64.9 \times 36.2 \mathrm{~mm}$ wide. The tranchet chisels are much smaller, averaging $49.6 \times 22.0 \mathrm{~mm}$, and weighing only 14 grams. The small dimensions of the bifacials seem to reflect both chronological trends and the intensive re-sharpening of working edges, as indicated by the high proportions of the tranchet spalls. ${ }^{35}$

\section{THE BLADE CACHE}

Although this cache of 58 bidirectional naviform blades was found in Layer VI it was not included in the analyzed sample described above. Doing so would misrepresent the technological ratios in the assemblage in favour of the bidirectional blade technology. Contextually the cache was deposited in a fill, $c a 60 \mathrm{~cm}$ beneath and adjacent to, but outside the eastern wall of a plaster-floored quadrilateral building. ${ }^{36}$ It is assumed that the blades were bound together in an organic container as they were found tightly packed.

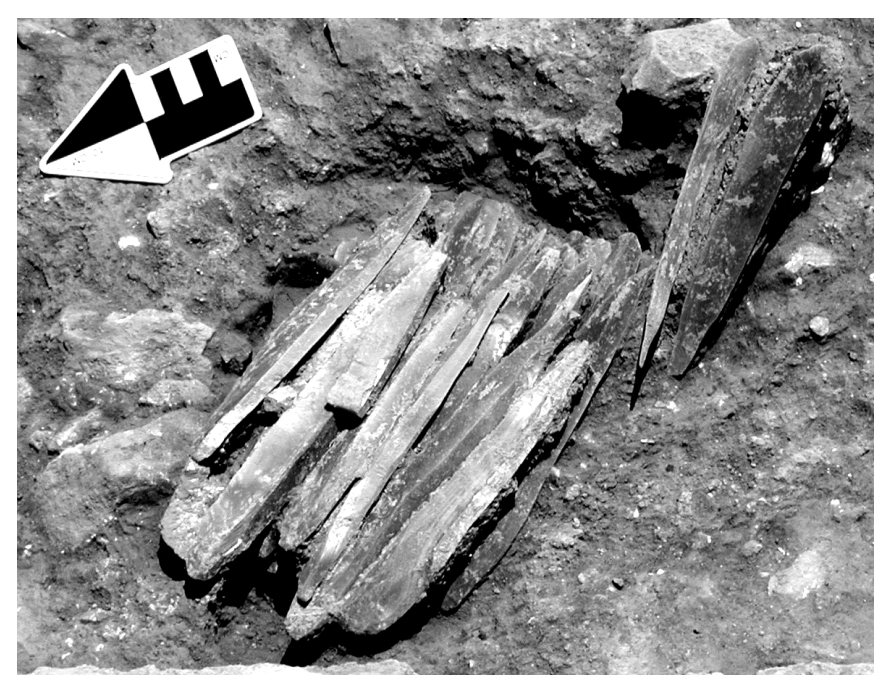

Fig. 15: Blade cache.

Ongoing refitting demonstrates that all 58 blades in the cache derive from two flint cobbles of high quality lustrous flint

35. BARKAI, 2005: fig. 83.

36. KHALAILY et al., 2007. (fig. 15). Both are on high quality flint with thin parallel veins, one being light pink and the other light brown, and could derive from the same geologic formation. Small quantities of this flint type were identified amongst the debitage within the analyzed assemblage, all obtained from bidirectional blade technology that could even derive from the same reduction sequences as the cached blades.

The origin of this flint source remains uncertain, though the flint colour and texture seems to resemble the natural pinkish flint of Ain Ghazal [O.B. personal observation]. The source of the latter was identified at Wadi Huweijir not far from Ain Ghazal. ${ }^{37}$ Since Motza is located in a similar geographical setting as Ain Ghazal but on the west side of the Rift, it is quite possible that such an exposure was available near Motza; both sites are located in similar geological settings (Cenomanian and Quaternary formations), and an exposure of the same flint formation has been identified near Har-Adar, ca $5 \mathrm{~km}$ northwest of Motza.

Except for one item with minimal retouch, none of the blades in the cache are retouched. Most of the blades are very standardised and symmetrical, having convergent pointed ends. Their sizes are extraordinary, the average length being $14.8 \mathrm{~cm}$ (sd 2.21). All are extremely elongated as indicated by the mean $\mathrm{L} / \mathrm{W}$ ratio of $1: 7$. All blades in the cache display careful preparation prior to detachment as indicated by intensive abrasion that reached sometimes approach polishing. This enabled a high degree of precision during blank removal and was probably one of the major reasons for the absence of knapping accidents, i.e. hinging or significant overpassing, during blade production.

Preliminary refitting results indicate that 46 blades in the cache derive from a single reduction sequence with no core rejuvenation. This aggregate displays a distinctive knapping method that focused on the production of predetermined pointed blades. The method is characterized by two major concepts. The first involves the efficient and standardised exploitation of the removal surface as attested to by hardly any overpassing on most blades and the absence of epsilon, i.e. 'cleaning up', blades. The second is the lack of rejuvenation stages during the blade production, i.e. core tablets, neocrêtes, and the like.

\section{SUMMARY}

It is quite clear that the ad hoc flake technology is dominant in the assemblage, although there is a preference for blade

37. QUINTERO, 1996. 
blanks amongst the tools. As described above it is apparent that this EPPNB assemblage in Layer VI at Motza comprises elements of both earlier PPNA and later PPNB lithic traditions. On one hand, the PPNA traditions include tranchet bifacials (which do continue into the PPNB), Khiam points and bladelet production. The tranchet bifaces are extremely small and light. These are typical PPNA characteristics, as evident at sites such as Netiv Hagdud and Modi' in. ${ }^{38}$ However, when compared to the MPPNB bifacials, it is clear that those from Motza differ in these aspects and in the absence of polish.

Amongst the arrowheads the Khiam point is a distinctive PPNA tool type. Yet, quantitatively, the Khiam points at Motza differ from those in PPNA assemblages as they are only the third-most frequent arrowhead type ( $c a 6.2 \%$ of the projectiles). Qualitatively it is important to note that in PPNA assemblages in the southern Levant most Khiam points were made on bladelet blanks. However, here in Motza blades and flakes were the favored blanks, resulting in an unusual stubby configuration; accordingly the Khiam points at Motza should not be seen as intrusive PPNA elements.

The third element that resembles PPNA traditions is the presence of a bladelet technology, as expressed in the high frequency of the bladelet cores, although microliths are scarce in the assemblage.

The clear PPNB features in the assemblage relate to the presence of a sophisticated bidirectional blade technology, albeit in extremely small quantities, as most convincingly demonstrated by the blade cache. It seems that this technology was designated primarily for the production of sickle blades, since all are made on bidirectional blade blanks. The preferential use of bidirectional blades is also evident within some arrowhead sub-types, which were manufactured both on flakes and on blades. This differs from the situation in MPPNB assemblages, where most formal tools (i.e. projectiles, sickles, transverse burins, borers, etc.) were fashioned on bidirectional blades.

The vast majority of arrowheads are of Helwan and Jericho types. The Helwan point is a distinctive EPPNB type, although they continue to appear in MPPNB contexts elsewhere. The shorter sub-type that was shaped on flake blanks is very similar to the Helwan points found at the EPPNB site of Nahal Lavan 109, in the western Negev; ${ }^{39}$ while the more elongate Helwan point sub-type on bidirectional blades at Motza resembles the northern type found at Mikhmoret, Hurvat Galil and Tell Aswad ${ }^{40}$.

\footnotetext{
38. BARKAI, 2005.

39. BURIAN et al., 1999.

40. CAUVIN, 1995; GOPHER, 1997.
}

The Jericho points are also equally shaped on both flake and blade blanks. The former seem to be absent from other reported PPNB assemblages, possibly due to confusion with Haparsa points, which have often been considered as Late Neolithic intrusions. The Jericho points on blades are similar to those found at E/MPPNB occupations such as Munhata 6 and the early phase of Kfar HaHoresh. ${ }^{41}$ Occasionally sickle blades were recycled and used as blanks for Jericho points. These phenomena are common in other PPNB assemblages ${ }^{42}$.

\section{NOTES ON THE OBSIDIAN ARTEFACTS}

The obsidian assemblage recovered in the EPPNB layer comprises 432 artefacts (tab. 2). These include cores, waste and tools thus consisting most if all of the reduction sequence. Technologically, the main mode of production was oriented toward blade and bladelet production from unidirectional cores.

Various morphometric characteristics such as abraded butts, intersecting scars (some are bidirectional), and uneven thickness along the blade blanks gives the impression that most were preformed by direct percussion using a soft hammerstone. It is worth noting that similar characteristics were also noted for the manufacture of blades in the flint assemblage.

By contrast the pressure flaking technology that is known from the northern Levant ${ }^{43}$ is rare, and only a few obsidian items at Motza display this type of retouch (fig. 16: 6). Exceptional is an elongated projectile/pointed bladelet that is made on blackish opaque obsidian. The bladelet morphometric attributes include converging lateral edges with parallel scars, and extremely thin trapezoidal cross-sections. It is thus likely that this particular artefact was transported to Motza as a final product.

All of the cores are exhausted, having multiple platforms with irregular debitage surfaces with both blade and flake scars. Three cores are on flakes and display removals on both sides of the flakes. The 33 tools include: retouched blades, projectile points, varia, sickles, retouched pieces and a perforator (tab. 4). The triangular, clover-leaf sub-type Helwan point $(\mathrm{n}=5)$ is the dominant variant amongst the projectiles (fig. 16: 1-3). It is interesting to note that the shaping method is identical to that for those points on flint. The other obsidian projectiles include one Khiam point and four fragments.

From the above, it is clear that obsidian knapping took place on-site, complementary to the flint. The raw material was

\footnotetext{
41. GOPHER, 1989b; A.N.G.-M. and O.B., personal observations

42. KHALAILY and MARDER, 2003.

43. WILKE, 1996; ASTRUC et al., 2007.
} 


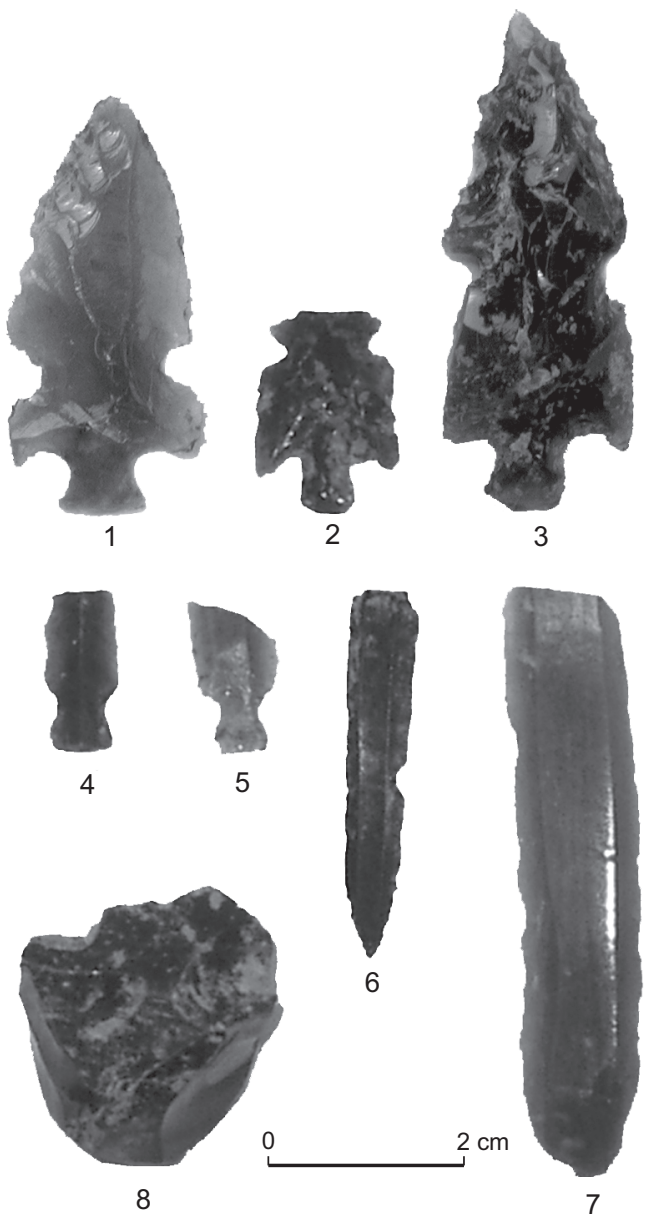

Fig. 16: Obsidian artifacts. 1-3, Helwan points; 4-5, Khiam points; 6-7, bidirectional blades; 8 , core.

imported through long distance exchange and was intensively worked locally. This conclusion is based on the similar methods of blank and tool production used for both the obsidian and flint assemblages. By contrast, a few pressure flaked blades are indicative of them being brought to the site as final products.

\section{ART AND CULTIC OBJECTS [A.E.R.]}

Among the small objects recovered from Layer VI, two items are of particular importance and will be described in detail. The first is a votive clay figurine and the second a green stone pendant.

\section{CLAY FIGURINE}

The small figurine derived from fills of the middle phase of Layer VI (Locus 4040, basket 40644) (fig. 17: 1). It depicts a standing male figure, with the head broken. The preserved height is $30 \mathrm{~mm}$, the maximum width being $17 \mathrm{~mm}$. The clay is well levigated and includes organic tempers, yet it is poorly fired resulting in black colouration and a smooth but uneven surface. The figurine has no arms or hands. The waist is clearly marked and the pelvis and buttocks are visibly distinguished. The legs extend from the torso, while the knees are shown by differences in the thickness of the thighs and the calves. A male pudendum is depicted by a small pinch of clay under the stomach. The figurine has a flat profile, making it nearly two-dimensional.

The closest iconographic parallels are the lime-plaster statues from Ain Ghazal. ${ }^{44}$ While the statues of Ain Ghazal differ in size and raw material, remarkable stylistic similarities exist. As in the example from Motza a number of the Ain Ghazal statuettes stand in the same position, with or without small arms, and have flat profiles.

\section{STONE PENDANT}

A small object made of green stone also emerged from the fills of Layer VI (Locus 4050, basket 40836) (fig. 17: 2). The item is the upper half of a stone figurine. The object was broken in half and then reused as a pendant; the drilled hole was made after the break on the figurine's torso. The preserved height of the figurine is $17 \mathrm{~mm}$ and the maximum width is $11.5 \mathrm{~mm}$. The provenance of the raw material is in north Syria (Y. Goren, personal communication).

The details of the human anatomy are modeled by incising, grooving and polishing. At the front of the figurine a schematic face protrudes, demarcated by two diagonal incisions. The face resembles a bird with its beak protruding. Two additional incisions divide the neck from the body, as if the figure is wearing a garment. Arms were also indicated by incisions placed on both sides of the body, with broad shoulders. The iconography of the figure sets the triangle as a leitmotiv. The face, neck, front and back form three downward pointing triangles. The body with broad shoulders also has a triangular shape. Some aspects of this figurine resembles a clay object at Basta; ${ }^{45}$ however, the origin of the raw material and the unfamiliar style of the pendant for the

44. ROLLEFSON and SIMMONS, 1985 and 1986; TUBB and GRISSOM, 1995.

45. GEBEL et al., 2004: 39 

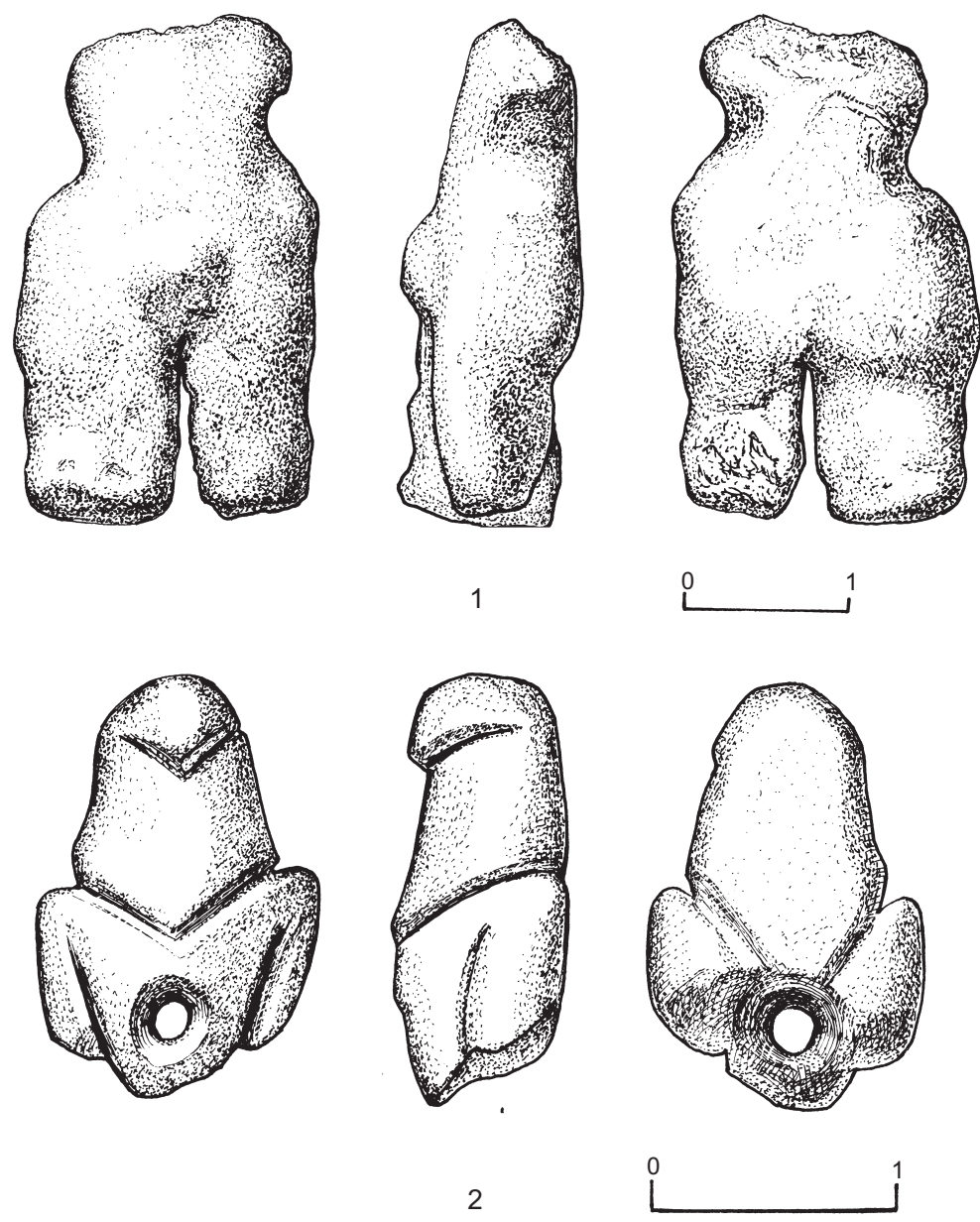

Fig. 17: Figurines.

southern Levant indicate that the item may have been imported and reused, emphasizing the high value of this object.

\section{FAUNAL REMAINS [L.S.H.]}

The large faunal assemblage from the EPPNB (7,021 identified bones) is dominated by mountain gazelle (Gazella gazel$l a-58 \%)$. A hunting pattern focusing on gazelle is similar to that found in many Pre-Pottery Neolithic and Epipalaeolithic sites in the southern Levant (tab. 6) ${ }^{46}$ Other mammals found include aurochs (Bos primigenius), wild boar (Sus scrofa), goat (Capra sp.), fox (Vulpes vulpes), wild cat (Felis silvestris), hare

46. BAR-OZ, 2004; BAR-OZ et al., 2004.
(Lepus capensis), rodents and insectivores. The assemblage also contains tortoise (Testudo graeca) and bird bone remains.

Of special interest are the abundant aurochs remains $(\mathrm{NISP}=57)$ in the EPPNB layer deposited in a single pit (L4005). Although many of the bones are articulated, no signs of butchery or burning were noted, suggesting a symbolic or ritual context. ${ }^{47}$

The faunal assemblage from the MPPNB (913 identified bones) is also dominated by mountain gazelle (41\%), although less markedly so than in the EPPNB, while the frequency of tortoise and goat increases. Goat remains could not be identified to species due to the lack of horns, but are probably wild, as indicated by their low frequency in the assemblage.

47. And see GORING-MORRIS and HORWITZ, in press for details of a similar 'Bos pit' at E/MPPNB Kfar Hahoresh. 


\begin{tabular}{|c|c|c|c|c|c|}
\hline & \multirow[b]{2}{*}{ Species } & \multicolumn{2}{|c|}{ EPPNB } & \multicolumn{2}{|c|}{ MPPNB } \\
\hline & & NISP & $\%$ NISP & NISP & $\%$ NISP \\
\hline \multirow[t]{4}{*}{ Big game } & Gazella gazella & 4,036 & 57.48 & 377 & 41.29 \\
\hline & Sus scrofa & 656 & 9.34 & 110 & 12.05 \\
\hline & Capra sp. & 201 & 2.86 & 96 & 10.51 \\
\hline & Bos primigenius & 150 & 2.14 & 27 & 2.96 \\
\hline \multirow[t]{4}{*}{ Small game } & Vulpes vulpes & 816 & 11.62 & 90 & 9.86 \\
\hline & Testudo graeca & 313 & 4.46 & 136 & 14.90 \\
\hline & Lepus capensis & 259 & 3.69 & 11 & 1.20 \\
\hline & Felis silvestris & 232 & 3.30 & 29 & 3.18 \\
\hline \multirow[t]{3}{*}{ Other species } & Aves & 91 & 1.30 & 9 & 0.99 \\
\hline & Mollusca & 180 & 2.56 & 16 & 1.75 \\
\hline & Rare species & 87 & 1.24 & 12 & 1.31 \\
\hline \multicolumn{2}{|c|}{ TOTAL NISP } & 7,021 & & 913 & \\
\hline
\end{tabular}

Tab. 6: Main faunal taxa (NISP) identified in Motza Early and Middle PPNB.

The dominant carnivore in both assemblages is the red fox. In the EPPNB assemblage it is the second most common game. A high frequency of the fox remains bear signs of burning (15\%), and the remains were not articulated. These observations suggest that the presence of fox at the site could not be attributed to it being a scavenger alone, but that the fox was a dominant game, consumed by the inhabitants of the site.

Detailed taphonomic and zooarchaeological research was conducted, focusing on the gazelles. The state of bone preservation is exceptionally high as evident from the low percentage of weathered bones, the absence of signs for carnivore activities, and the representation of the entire spectrum of bonesincluding those of young animals, small game, and low density and porous skeletal elements. ${ }^{48}$

Analysis of the EPPNB gazelles' age distribution, as assessed by epiphyseal closure and tooth wear, shows a proportion of juveniles that is not different from a recent herd age distribution. ${ }^{49}$ Sex ratios, assessed by morphometric analysis of gazelle body size, suggest that hunting was random, without a sex preference. ${ }^{50}$ These results suggest that gazelles were killed in proportion to their abundance in the living herd, and that no selective culling or herd management that could have led to changes in the gazelle population was practiced at Motza.

48. DAVIS, 1983; MUNRO, 2004.

49. BAHARAV, 1974.

50. SAPIR-HEN et al., in preparation.

\section{HUMAN REMAINS [F.B.]}

Nine graves, as well as two other occurrences with many human bones (L4037 and L4081) were recovered from the EPPNB layer of Motza. Apart from one burial (L5050) that is probably associated with the upper phase of the EPPNB, the remaining eight graves are contemporaneous with the middle phase of the EPPNB occupation. The graves were found in both sectors, upper and lower; however the majority was grouped together within squares $\mathrm{N}-\mathrm{O} 19$ of the upper sector, an open area between the main structures. This area could be one of the burial places within the site. The following is a description of the graves and their state of preservation.

Locus 4037. This locus was found in the upper excavated area, in square O19. It contained human bones scattered over a large surface and was mixed with a large amount of faunal remains (most of them burnt) and pieces of lime plaster. The

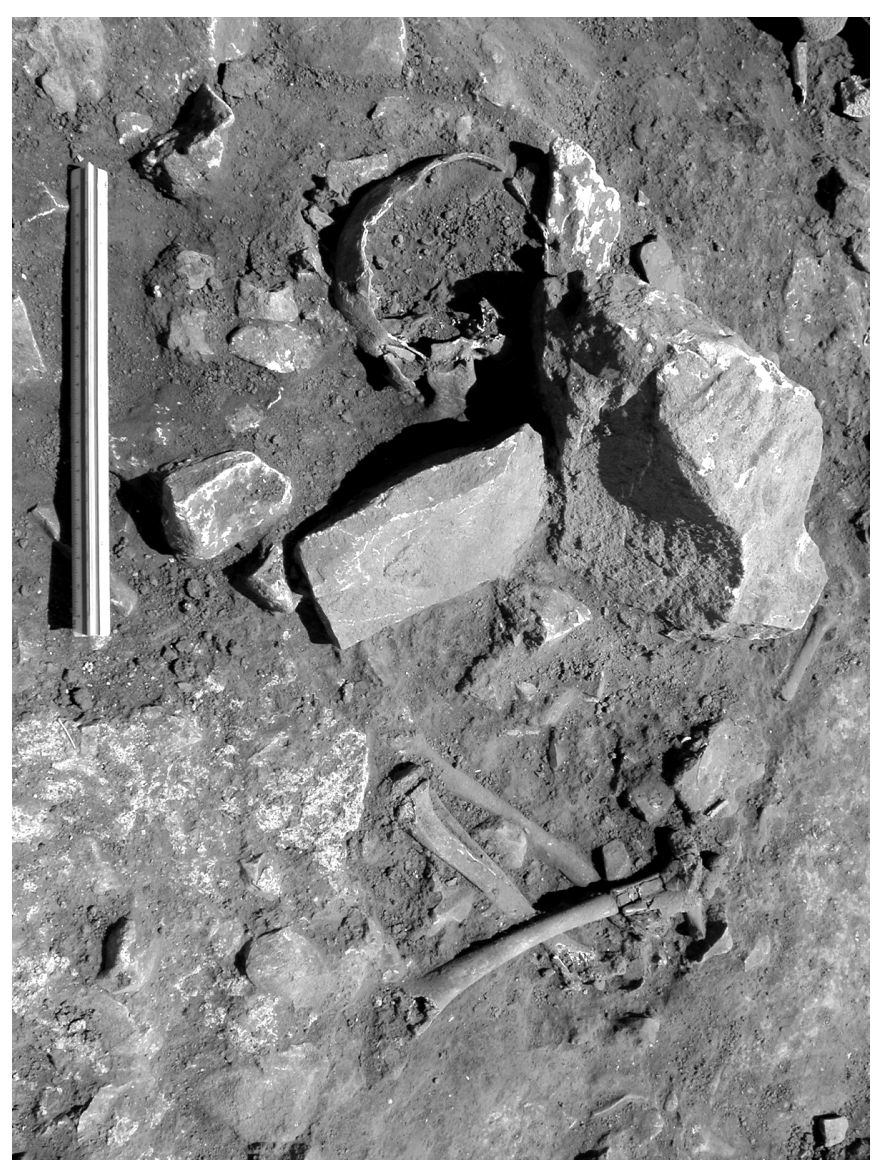

Fig. 18: Primary burial of a child (L4041) laying in a flexed position on its right side. 


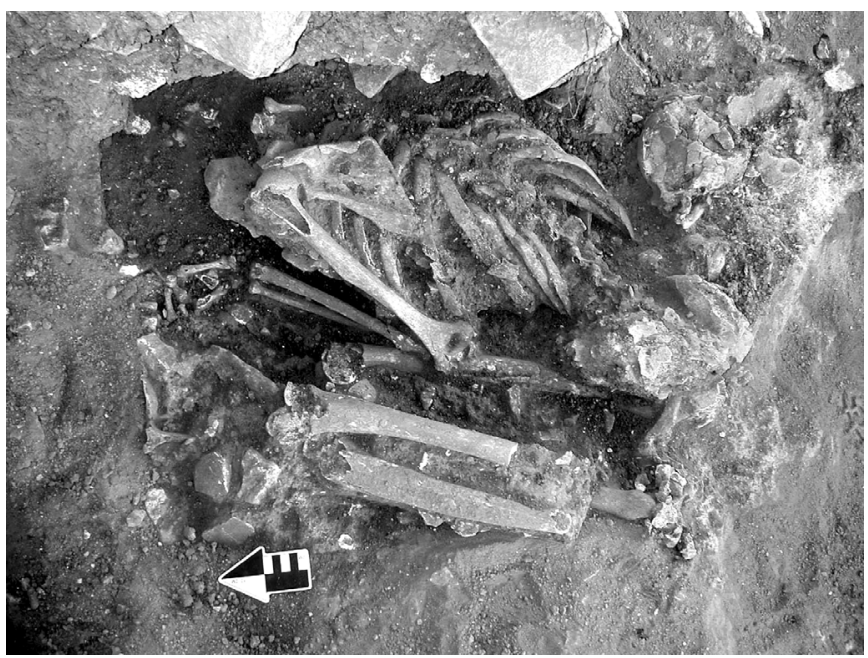

Fig. 19: Primary double burial of a mature male (L4046) and a baby (L4047). The skull of the adult was removed at the end of the decay process.

human remains include: one complete adult mandible, fragments of long bones and parts of different skulls (right parietal, three fragmented occipitals of which one belongs to a child less than two years old). One of the adult occipitals is burnt and shows a graduation of colours from grey-blue to white. The assemblage from L4037 appears very heterogeneous, each piece of bone having a different taphonomic aspect. The calculated MNI is three individuals (two adults, one child) but according to morphological and taphonomic considerations each bone could belong to a different individual.

Locus 4041. This is the burial of a 7-9 year old child lying on its right side, the head positioned towards the north (fig. 18). The body was placed in a flexed position, the right hand facing the head and the left hand below the chin. Two large stones, one lying, one standing, were placed above the chest and neck of the child. The vertical one, ca $30 \mathrm{~cm}$ high, may have been a gravestone. The upper part of the skull was eroded and the left leg and both feet were disturbed by later events. Part of a plastered surface was found at the west edge of the top of the grave and may have been associated with the burial.

Loci 4046-4047. This is a primary double burial of a mature male adult with a baby of 3-9 month old (fig. 19). Both were oriented in a north-south direction. The adult was placed on the abdomen with the limbs tightly flexed on the left side of the body. The head of the adult is missing, most probably removed after decay of the soft tissues since the mandible and the first cervical are present. The baby was placed to the right of the adult, facing the lumbar part of its back. The southern edge of the grave was damaged by later disturbance and both skeletons were partly cut (the feet of the adult and the limbs of the baby are missing). The burial was covered by a layer of plaster ca $10 \mathrm{~cm}$ above the skeletons.

Locus 4049. Disarticulated human bones were found grouped together and mixed with animal bones, mainly gazelle (fig. 20). A pair of gazelle horns found not far to the north is probably associated with this burial as well. Other than one supplementary mandible, all the human bones are most probably part of the same individual, an adult male (4049a). Part of the left pelvis, scapula, and clavicle are present, as well as eight long bones, the mandible, the first left metatarsal, a few ribs and part of the cervical and thoracic vertebral column. No anatomical articulation was found in this assemblage (except vertebrae $\mathrm{C} 2$ to $\mathrm{T} 1$ which are fused together by hyperostosis), which is likely to be a secondary burial. The second mandible (4049b) has a taphonomic aspect different from the other bones, which indicates that it came from a different context before they were buried all together. The bones situated at the centre of L4049 are all burnt (from brown to black colouration), indicating the presence of a small hearth at the top of the grave.

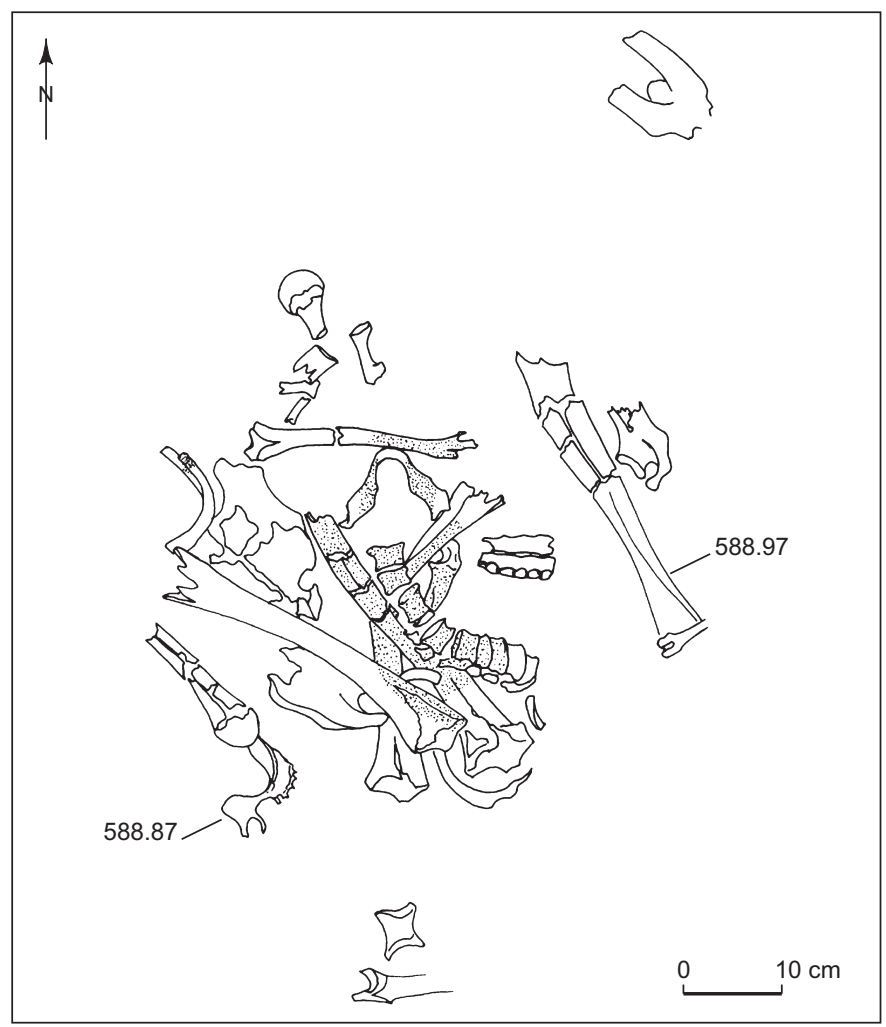

Fig. 20: Disarticulated human bones grouped together and mixed with animal bones with remnants of fire (L4049). 


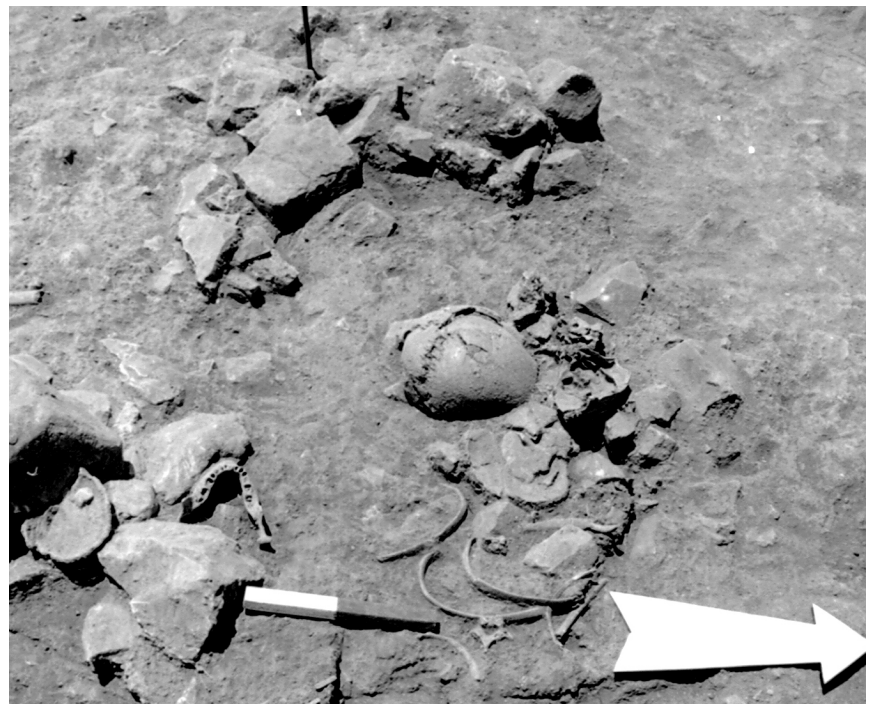

Fig. 21: Secondary burial of 5 individuals (L4054).

Loci 4054, 4050 and 4053. This is a secondary burial including a minimum of five individuals, mainly represented by skull fragments (fig. 21). The bones were associated with small angular stones and were surrounded on the west and the south by a small wall (W405). Most of the remains were grouped together at the centre of the structure but a few more were found scattered at the southern edge on the wall; these bones fit with those of the main assemblage. In this burial a complete skull and the mandible of an adolescent, along with another three fragmentary skulls of adults and a few bones of a 4-6 year old child (fragment of frontal, mandible, one vertebra and a few ribs) were found. Patches of plaster were found in the grave.

Locus 4063. This is the primary burial of a child of 1 to 2 years old that was buried in a depression. The skeleton is partial because it was disturbed by a later pit (L4067) dug into the south-eastern edge of the burial. The skull, mandible, part of the thorax, the right arm and a fragment of the left femur are preserved and indicate that the child was lying on its left side, possibly with limbs flexed. The body was placed on a large stone and surrounded by a squared structure made of plaster. The skeleton, the plaster and the top of the stone were approximately at the same level.

Locus 4081. Human remains were found under the plaster floor of structure L4031. The bones represent at least two individuals (a young adolescent and an adult), although the assemblage is heterogeneous and the real number of adults is likely to be higher. Other than a few lumbar vertebrae no anatomi- cal connections were preserved. No clear evidence of deliberate burial was found. This assemblage might also represent remains disturbed when the floor was leveled.

Locus 5039. This is a burial of a 1.5-2.5 year old child. Only the upper half of the skeleton was present. The bones were found scattered without any anatomical connections but mixed with pieces of plaster, as if the body was originally embedded within a plaster adhesive. This is most probably a primary burial later disturbed by a pit. Only the left half of the skull was present lying on a well-preserved concave plaster patch.

Locus 5050. This is a primary burial of a mature adult, sex unknown. The body was placed in a flexed position, lying on its right side oriented east-west. The skull was missing but the mandible and the cervical vertebrae are present. The skeleton lay directly on wall 216 and was covered by a stone heap (L2061).

Locus 5068. Remains of the skeleton of a 5-6 year old child were found above grave 5070, near wall 509. The skeleton is very partial (sacrum, pelvis, head of left femur, seven vertebrae, a few hand bones and ribs) and no articulation was noted.

Locus 5070. This is the burial of an adult female placed in a natural hollow in the bedrock. The body lay on its right side, tightly flexed and oriented south-east/north-west. The skull, mandible and the first four vertebrae are missing. Initially, the right hand was placed under the head and the left hand was in front of the face.

\section{PRELIMINARY REMARKS ON THE HUMAN REMAINS}

Considering the possible inter-dependence of the loci, the current MNI at Motza is 13, of which six are adults, one is an adolescent and six are children. Sex could be determined for three adult skeletons (one female and two males) with pelvic bones preserved ${ }^{51}$ age-at-death of the children was determined according to teeth calcification with a confidence interval of $95 \%{ }^{52}$ No particular burial selection based on age or sex can be seen within this current sample. In general, bones are wellpreserved but highly fragmented. Detailed metric and morphologic studies are in progress. Initial observations suggest that the group at Motza is heterogeneous in both robustness and cranial morphology. DNA samples were taken in the field and are in the process of being analyzed (M. Kaufman, personal communication).

51. BRUZEK, 2002

52. MOORREES et al., 1963a and b. 
Very few cases of dental pathologies were recorded: carries and abscess are absent and only one individual (L4046) displays slight lesions of enamel hypoplasia. Dental wear is usually slight and ante-mortem tooth loss is relatively rare (two cases). However many jaws, including those of young children, show dental calculus. Adult bone pathology affects mainly vertebrae, and was sometimes severe as in L4046, L5070 and L4049. Two healed fractures on a rib (L5070) and on a distal extremity of right ulna (L4046) were also identified. Children have signs of pathological bone reaction such as cribra orbitalia (L4054A) or periostosis mainly on the skull and mandible (L4054A, L5039, L4063 and L4037F). Porotic hyperostosis, considered as a marker of anemia, ${ }^{53}$ was also recorded on the parietal bones of a young child (L4063). These non-specific pathological markers are quite frequent considering the size of the sample.

\section{PRELIMINARY REMARKS ON FUNERARY TREATMENT}

Human burials were discovered in all excavated areas, including subfloor and courtyard burials. This discovery provides detailed evidence for a variety of burial types. They include primary (of one or two individuals) and secondary (of two or more individuals) burials. Primary burials are more numerous. No preference in the orientation of the bodies can be noticed (1 SE; $1 \mathrm{SW} ; 3 \mathrm{~N}$; $1 \mathrm{E}$ ); however, corpses were all placed in a flexed or tightly flexed position and most of them on the side, preferentially the right side (4 on the right side; 1 on the left side; 1 on the abdomen). All three primary graves of adults show evidence that skull removal probably took place after the end of the decay process, during a second stage of the funerary treatment. These partial primary burials as well as the secondary burials (i.e., L4049 and L4054) clearly show that skulls and infra-cranial remains are treated totally separately. The mandibles seem to have an intermediate status, sometimes treated like the skulls (L5050, L5070, L4054), and other times handled as infra-cranial bones (L4046, L4049). The removal of the cervical vertebrae together with the skull in the case of L5070 must be related to the partial state of decay of the body at the time of the reopening, because these vertebral joints are the most enduring and disconnect at a late stage from the occipital. ${ }^{54}$

53. STUART-MACADAM, 1992.

54. DUDAY, 2005.
The location of the graves, position of the body, removal of skull and presence of secondary burials show that the funerary customs at Motza conform to what we know from the other few EPPNB burials discovered thus far ${ }^{55}$ (other than Dja'de ${ }^{56}$ ). There is also a clear continuity from PPNA burial customs from the southern Levant. ${ }^{57}$ Despite the indisputable similarities, Motza does show a particularity: most of the graves were associated with remains of plaster. It was found either as a thin layer over the skeleton or surrounding the skeleton or, more frequently, as patches mixed in the filling of the grave. These preliminary observations indicate that plaster certainly played an important role in body treatment. The exact modality of using the plaster remains unclear: it may have been placed in the pit before the corpse was placed or right after the burial. In some cases a layer of sediment separated the body from the plaster. In one case, the plaster was used for building a real grave structure. The composition of the plaster itself is in the process of being analyzed and may help to understand this new phenomenon, which may have a significant link with the plaster modeling of skulls in the MPPNB period.

\section{BONE AND ANTLER TOOLS [G.L.D.]}

The bone tool industry from the EPPNB Motza contained 404 worked artefacts. They can be subdivided into 239 shaped objects, 50 specimens being identified as waste products and the remaining 115 were indeterminate (tab. 7). This tool assemblage is one of the largest, if not the largest PPNB assemblage known from the southern Levant despite the small area of excavation. In addition, the quantity of waste products, which contributes much to the reconstruction of tool shaping methods, is quite important in comparison to other sites. This is partly due to the systematic collection methods applied and to the fact that the faunal remains have been re-examined searching for bone tools.

As in most PPNB assemblages, the pointed objects were best represented in Motza. The most frequent tools within this group were awls, present in a variety of shapes and sizes (fig. 22). The assemblage also included needles, cutting pointed tools and very fine objects resembling Natufian pins. Most of these pointed tools seem to have been used for transformation

55. HERSHKOVITZ and GOPHER, 1988; CAUVIN, 1980.

56. COQUEUGNIOT, 2000.

57. LE MORT, 1992 and 1994; BELFER-COHEN et al., 1990; KUIJT et al., 1991; KUIJT and GORING-MORRIS, 2002. 


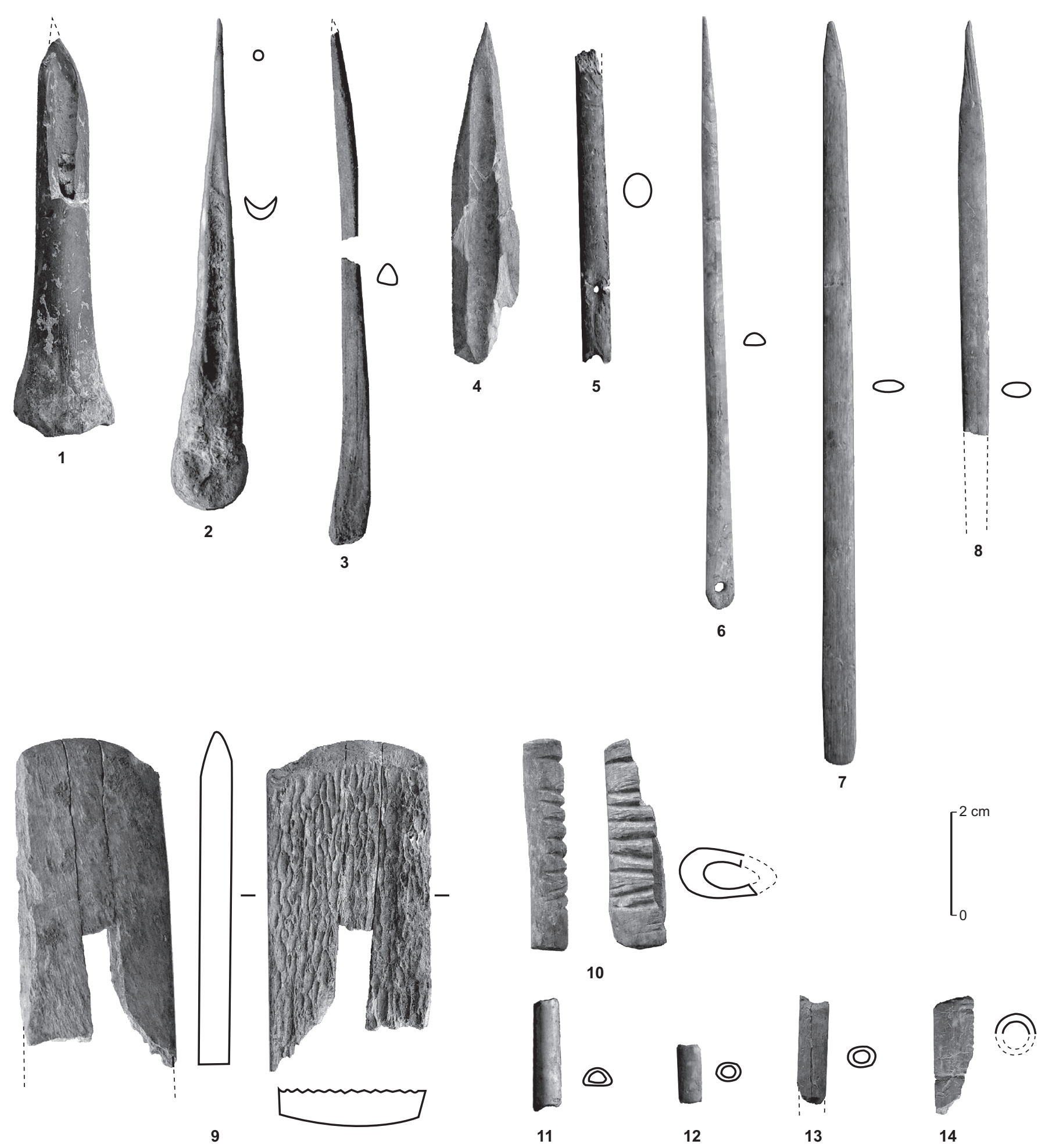

Fig. 22: Bone tools. 1-4, awls; 5-8, needles; 9, spatula; 10, incised bone; 11-14, bone beads. 
activities such as drilling. Nonetheless, one cannot exclude the possibility that some intensively worked pieces were used as arrowheads or for ornamentation. In addition to the perforating tools, the assemblage contained a significant number of cutting tools like tranchets and couteaux plats as well as some smoothing tools. One tubular object made of antler may be a handle. Only a few jewels were identified, including one perforated aurochs incisor and some tubular beads (see tab. 7). Other than the known types, some unique pieces were found, such as a tube with multiple transversal incisions on one side and another object with a semi-rounded distal end resembling a fan. This could be the tip of a spoon or of a cutting/smoothing tool comparable to Natufian and Sultanian items found in Jericho..$^{58}$

Like in most assemblages in the Levant, bone was used for shaping these objects. It originated from hunted animals. Cervid antlers were less common and their frequency is similar to cervid faunal remains at the site. The people from Motza often used the metapodials of small ruminants, mainly gazelles, for their awls, although they sometimes chose other body parts like the humerus, radius, ribs and even horn cores. Among the metapodials they chose metacarpals and metatarsals without any preference in modifying either end. For flat cutting and smoothing tools, they often chose ribs of medium and large game. They used long bones of small animals like hare, fox and bird for the tubular beads, an aurochs incisor for a pendant and a Dama antler for the handle and the fan-shaped object.

The presence of waste products together with shaped tools enabled the reconstruction of tool shaping techniques and the reduction sequence from raw material selection to the final object. To produce blanks percussion, sawing, grooving and entaillage were used, the last technique being particularly adapted to the fibrous structure of antler and exclusively applied to this material. To shape the blanks shaving and, less frequently, abrasion was used. Perforations were made by shaving in rotation or possibly by longitudinal grooving. All these techniques were applied following different schémas opératoires. Teeth pendants were directly shaped on the plain body parts, while some awls and cutting tools were shaped on simple splinters rapidly produced by percussion or selected among the kitchen waste. The handle, the tubular beads and the tube were made on blanks produced by transversally sectioning the bones, while some awls, needles and cutting tools were shaped on blanks produced by splitting the bone into two equal or multiple parts along the long axis.

58. MARSHALL, 1982.

\begin{tabular}{|l|c|}
\hline Types of objects & N \\
\hline Awls & 4 \\
\hline Associated fragments & 57 \\
\hline Needles & 2 \\
\hline Associated fragments & 2 \\
\hline Needles or perforated pins & 3 \\
\hline Associated fragments & 3 \\
\hline Small "pins"? & 3 \\
\hline Cutting pointed tools & 5 \\
\hline Associated fragments & 8 \\
\hline Flat pointed tool perforated at the end & 1 \\
\hline Fine pointed objects deeply shaped & 32 \\
\hline Other pointed objects & 25 \\
\hline Smoothing tools & 3 \\
\hline Cutting tools (burins) & 4 \\
\hline Cutting tools (tranchets) & 6 \\
\hline Associated fragments & 115 \\
\hline Cutting tools (couteaux plats) & 23 \\
\hline Flat tools, cutting or smoothing & 32 \\
\hline Cutting or smoothing tools & 1 \\
\hline Handles & 1 \\
\hline Pendants & 1 \\
\hline Beads & 1 \\
\hline Associated fragment & 1 \\
\hline Incised tube & 3 \\
\hline Waste & 6 \\
\hline Waste, blank or object associated with pointed objects \\
\hline Waste, blank or object associated with cutting pointed objects & 1 \\
\hline Waste, blank or object associated with awls & 2 \\
\hline Waste, blank or object associated with tranchets & 1 \\
\hline Waste, blank or object associated with cutting or smoothing tools & 7 \\
\hline Waste, blank or object associated with beads & 3 \\
\hline Undetermined & 2 \\
\hline ToTAL & 2 \\
\hline
\end{tabular}

Tab. 7: List of bone objects from Layer 6 of Motza.

It is also worth mentioning the frequency of rejuvenation and recycling at the site. The people of Motza did not discard their objects after use. Our observations indicate that some tools were recycled or transformed into other objects after they were damaged.

In conclusion, the EPPNB Motza bone tools display a wide range of objects probably reflecting diverse domestic 
activities. Most types are known from earlier Natufian and Sultanian assemblages. The plethora of fine and well-shaped pointed objects is worth mentioning, as at Natufian Mallaha. ${ }^{59}$ Indeed raw material preferences are like those of the Natufian and the Sultanian cultures. Nonetheless, they did not prioritize the proximal ends of metapodials like the Natufians from Mallaha or Hayonim Cave, ${ }^{60}$ but both ends, like the Sultanians of Jericho. The preference for distal ends has been noted from the MPPNB onwards. ${ }^{61}$

The main conclusion of this preliminary analysis on the bone tools from EPPNB Motza is that the bone industry has much in common with Natufian and PPNA industries, especially in the types of objects and in raw material selection.

\section{DISCUSSION}

The recent excavations at Motza have revealed two distinct Pre-Pottery Neolithic layers: Layer V, which dates to the M/ LPPNB; and Layer VI, lying directly over bedrock, which represents the earliest occupation in this part of the site, attributed to the EPPNB. Distinction between these two layers is facilitated by the nature of the fill, the radiometric dates and the material culture remains. No remains from the PPNA period are known from the site, although a LPPNB occupation horizon has been reported down-slope, ca $300 \mathrm{~m}$ away from our excavation areas. ${ }^{62}$ The data presented above clearly demonstrate that Motza was a large and long-lasting Neolithic site, extending over a total of $c a 9$ hectares.

Given the debate concerning the status of the EPPNB in the southern Levant the following discussion summarizes the main characteristics of Layer VI. The $2 \mathrm{~m}$ thick occupational level contains distinctive architectural remains that differ from those of Layer V. Layer VI consists of several domestic dwellings and segments of large and thick walls, perhaps related to public features. While the architectural features of Layer $\mathrm{V}$ consist of various rectangular structures with typical limeplastered floors and underlying human burials, the dwellings of Layer VI consist of rounded and rectangular buildings, both with plaster floors. The plaster was fabricated from local limestone and it seems that the lime was well sifted as indicated by

59. LE DOSSEUR in VALLA et al., 2004.

60. CAMPANA, 1991.

61. LE DOSSEUR, 2006.

62. EISENBERG and SKLAR, 2005. the small quantities of inclusions. The plastered floor was burnished and traces of red pigment were discerned on the floor of the rounded structure, suggesting its decoration. Following use during the Epipalaeolithic, there is little evidence for the systematic use of plaster during the PPNA, but it was clearly in common use by the EPPNB at Motza.

The EPPNB flint assemblage at Motza displays a combination of the continuation of the earlier PPNA traditions, together with the introduction of new technological innovations. The latter includes the transition from the production of short to long blade blanks, as demonstrated by the cores, waste material and tools. Nevertheless, the main focus of blank production was on flakes, albeit with formal tools preferentially being made on blades. Another important development is the appearance of bidirectional blade technology and its characteristic products, although naviform blade technology is rare amongst the cores and the debitage, with the exception of the cache and some formal tool types. Amongst the tools some derive from the PPNA tradition, as demonstrated by the Khiam point variants and the tranchet bifacials. Nevertheless at Motza both types display distinctive characteristics that set them apart from their PPNA counterparts; the Khiam points at Motza assemblage are mostly on flakes rather than blades, while the Motza bifacials are smaller and lighter.

The formal tools are dominated by Helwan and Jericho points, with many of the former being made on bidirectional blades in the north Levantine mode.$^{63}$ Most sickle blades are also fashioned on bidirectional blanks.

The obsidian industry at EPPNB Motza is profuse, in the form of cores and waste materials as well as tools; this is not surprising, given its abundance in some PPNA sites as well as at EPPNB Nahal Lavan 109 in the western Negev. ${ }^{64}$

The picture that derives from all the above evidence at Motza is one of considerable local continuity from the local Sultanian PPNA, including long distance exchange networks extending to the north, together with innovations that were to become the hallmarks of the later PPNB. Whether the innovations reflect endemic developments, or the diffusion of such materials/technologies, or combinations thereof remains open to debate; in the case of diffusion this could have involved some actual population movements or occasional visits by specialists (e.g., flint knappers). Whatever the case, the evidence at Motza indicates that cultural contacts between

63. GOPHER, 1994

64. GOPHER et al., 1998; BURIAN and FRIEDMAN, 1988; BURIAN et al., 1999. 
the southern and northern Levant were well-established during the EPPNB.

The EPPNB faunal remains at Motza contain a wide range of species, with mountain gazelle (Gazella gazella) the dominant species. This preference for gazelle continues Epipalaeolithic and PPNA hunting patterns in the southern Levant. ${ }^{65}$ By the MPPNB at Motza as well as elsewhere in the region gazelle hunting was still important, but declined as goats were introduced. ${ }^{66}$

Gazelle bones were preferred for manufacturing bone tools, again continuing earlier practices; ${ }^{67}$ but this pattern differs from both Natufian and MPPNB preferences. However, characteristics of the EPPNB Motza bone industry still have much in common with the Natufian.

The presence of animal and human figurines provides some indications concerning the symbolic world of the EPPNB habitants. Stylistically, the small human figurine resembles the later and much larger MPPNB statues at Ain Ghazal; ${ }^{68}$ the animal figurines also likely relate to ritual activities. The discovery of pendants on exotic raw materials likely indicates that such ritual items were also part of extensive exchange networks.

The investigations at Motza have also included more than a dozen ${ }^{14} \mathrm{C}$ datable samples. Rigorous pre-screening and pretreatment methods were applied to ensure that the dated samples are uncontaminated and provided highly reliable results. The series of dates obtained display internal homogeneity between the charcoal and the bone samples, and provide a range between ca $8500-8200$ cal. BC (tab. 1). This is similar to the EPPNB dates obtained at Tell Aswad and Horvat Galil. ${ }^{69}$ However, other southern Levantine EPPNB dates, such as those from Sefunim cave and Nahal Oren derived from more problematic contexts and should be viewed with caution. ${ }^{70}$ It has been asserted that the dates from late PPNA Zahrat adhDhra 2, adjacent to the Dead Sea, correspond to the early stages of the EPPNB (up to $8600 / 8500$ cal. BC). ${ }^{71}$ In this context it is important to note that Zahrat adh-Dhra 2 is a relatively short-lived, single phase settlement displaying material culture remains typical of the later PPNA. Of the nine ${ }^{14} \mathrm{C}$ dates provided by the site, all but one fall between $8800-8600$ cal. BC. Hence, in light of the results from Motza, the vast majority of the Zahrat adh-Dhra 2 dates still fall within the later PPNA in the southern Levant (8600 cal. BC).

\section{CONCLUDING REMARKS}

In light of the above evidence we believe that the secure stratigraphic context of the recent investigations in Layer VI at Motza, in conjunction with the distinctive characteristics of the material culture remains and the series of radiometric dates together have conclusively demonstrated the presence of a major EPPNB occupation at the site.

Nevertheless, the origins of the PPNB in the south/central Levant remain somewhat obscure. ${ }^{72}$ It has been suggested, based on lithic technology and domestication processes, that the PPNB koine first emerged in the northern Levant and then diffused southwards uniformly. ${ }^{73}$ However, the results from Motza appear to strongly support the evidence from several other sites in the southern Levant that the PPNB developed locally. ${ }^{74}$ Settlement patterns clearly shifted significantly between the PPNA and MPPNB, the causes for which remain uncertain. ${ }^{75}$ Still, we believe that the PPNB, like the PPNA, emerged more or less simultaneously in several core areas in the Levant, including the southern Levant, each with distinctive regional differences. Some elements of the PPNB cultural repertoire may indeed have emerged initially in the northern Levant, specifically along the middle Euphrates; but other characteristic components of the PPNB cultural repertoire, including some relating to the socio-ritual sphere, like the use of plaster, burial practices (such as skull removal and modeling), building traditions, and figurines clearly derived from a local southern Levantine milieu. These different core areas were (and had been previously, during the PPNA) in mutual cultural contact through exchange systems.

The recent excavations at EPPNB Motza demonstrate a combination of continuity from the local PPNA Sultanian, together with innovations heralding the beginning of the characteristic PPNB world. Together these demonstrate that questioning the very existence of the EPPNB in the southern Levant is no longer a relevant issue.

65. BAR-OZ, 2004.

66. HORWITZ et al., 2000.

67. e.g., MARSHALL, 1982.

68. ROLLEFSON, 1983, 1998 and 2001; BIENERT, 2004.

69. STORDEUR, 2003; GOPHER, 1989a.

70. RONEN, 1988.

71. EDWARDS et al., 2004: 21.

72. HORWITZ et al., 1999.
73. e.g., EDWARDS et al., 2004.
74. GOPHER, 1996.
75. GORING-MORRIS and BELFER-COHEN, 1997. 


\section{ACKNOWLEDGEMENTS}

The Authors wish to thank the Israel Antiquities Authority for permitting the publication of materials from the Motza excavation. The study of the human remains received the financial support of the French Ministry of Foreign Affairs (Bourse Lavoisier, MAE) and our grateful thanks also goes to Prof. P. de Miroschedji, director of the Centre de recherche français de Jérusalem who provided us with excellent working conditions. Thanks also to L. Zieger, M. Smilanski and O. Dobovzkia for drawing flint artefacts and skeletal remains. This study was partially sponsored by the Dr. S. Krauthammer Chair in Archaeology.

Hamoudi KHALAILY

Israel Antiquities Authority

POB 586, Jerusalem 91004 - ISRAEL

hamudi@israntique.org.il

Ofer BAR-YOSEF

Peabody Museum

11 Divinity Ave.

Cambridge, Massachussetts 02138 - USA obaryos@fas.harvard.edu

Omri BARZILAI

Israel Antiquities Authority POB 586, Jerusalem 91004 - ISRAEL msomry@mscc.huji.ac.il

Elizabetta BOARETTO

Radiocarbon Dating and Cosmogenic Isotopes Laboratory, Kimmel Center for Archaeological Science, Weizmann Institute of Science 76100 Rehovot - ISRAEL

Dept. of Land of Israel Studies and Archaeology Bar-Ilan University, 59100 Ramat Gan - ISRAEL elisa@wisemail.weizmann.ac.il

Fanny BOCQUENTIN CNRS-UMR 7041 ArScAn

21, allée de l'Université 92023 Nanterre Cedex - FRANCE fanny.bocquentin@mae.u-paris10.fr

\section{BIBLIOGRAPHY}

ABBÈs F.

2003 Les outillages néolithiques en Syrie du Nord: méthode de débitage et gestion laminaire durant le PPNB. Oxford (BAR Int. Ser. 1150).

ALON D., MintZ G., COHEN I., Weiner S. and BOARETTO E.

2002 The Use of Raman Spectroscopy to monitor the Removal of Humic Substances from Charcoal: Quality Control for ${ }^{14} \mathrm{C}$ Dating of Charcoal. Radiocarbon 44: 1-11.
Gaëlle LE DOSSEUR

CNRS-UMR 7041 ArScAn

21, allée de l'Université

92023 Nanterre Cedex - FRANCE gledosseur@hotmail.com

Anna EIRIKH-ROSE

Israel Antiquities Authority POB 586, Jerusalem 91004 - ISRAEL anna@israntique.org.il

\section{A. Nigel GORING-MORRIS}

Institute of Archaeology

The Hebrew University of Jerusalem Jerusalem 91905 - ISRAEL goring@mscc.huji.ac.il

Zvi GREENHUT Israel Antiquities Authority POB 586, Jerusalem 91004 - ISRAEL zvi@israntique.org.il

Ofer MARDER Israel Antiquities Authority POB 586, Jerusalem 91004 - ISRAEL oferm@israntique.org.il

Lidar SAPIR-HEN Dept. of Zoology, Faculty of Life Sciences Tel-Aviv University Tel-Aviv 69978 - ISRAEL Lidar.sh1@gmail.com

Mirav YIZHAQ

Radiocarbon Dating and Cosmogenic Isotopes Laboratory, Kimmel Center for Archaeological Science, Weizmann Institute of Science, 76100 Rehovot - ISRAEL Yizhaq@paradigmgeo.com

ASTRUC L., GRATUZe B., PELEgRIN J. and AKKeRMANS P.

2007 From Production to Use: A Parcel of Obsidian Bladelets at Sabi Abyad II. In: ASTRUC L., BINDER D. and BRIOIS F. (eds), Technical Systems and Near Eastern PPN Communities: 327-341. Antibes: Édition APDCA.

BAHARAV D.

1974 Notes on the Population Structure and Biomass of the Mountain Gazelle, Gazella gazella. Israel Journal of Zoology 23: 39-44.

BARKAI R.

$2005 \quad$ Flint and Stone Axes as Cultural Markers: Socio-Economic Changes as reflected in Holocene Flint Tool Industries of the Southern Levant. Berlin: ex oriente (SENEPSE 11). 
BAR-OZ G.

2004 Epipaleolithic Subsistence Strategies in the Levant. A Zooarchaeological Perspective. Boston: Brill Academic Publishers (American School of Prehistoric Research Monograph Series 3).

BAR-OZ G., DAYAN T., KAUFMAN D. and WEINSTEIN-EVRON M.

2004 The Natufian Economy at el-Wad Terrace with Special Reference to Gazelle Exploitation Patterns. Journal of Archaeological Science 31: 217-231.

BAR-YOSEF O

1981 The "Pre-Pottery Neolithic" Period in the Southern Levant. In: Cauvin J. et Sanlaville P. (éd.), Préhistoire du Levant : 551570. Paris : Éditions du CNRS.

2001 From Sedentary Foragers to Village Hierarchies: The Emergence of Social Institutions. In: RUNCIMAN G. (ed.), The Origin of Human Social Institutions: 1-38. London: Oxford University Press.

BAR-YOSEF O. and GOPHER A.

1997 An Early Neolithic Village in the Jordan Valley Part 1: The Archaeology of Netiv Hagdud. Cambridge: Peabody Museum of Archaeology and Ethnology, Harvard University (American School of Prehistoric Research Bulletin 43).

BELFER-COHEN A., ARENSBURG B., BAR-YOSEF O. and GOPHER A.

1990 Human Remains from Netiv Hagdud - A PPNA Site in the Jordan Valley. Mitekufat Haeven - Journal of the Israel Prehistoric Society 23: 79-85.

BIENERT H.D

2004 The Pre-Pottery Neolithic B (PPNB) in Jordan: First Steps toward Proto-Urban Societies. In: BIENERT H.D., GEBEL H.G.K. and NEEF R. (eds), Central Settlements in Neolithic Jordan: 21-40. Berlin: ex oriente.

\section{BRONK RAMSEY C.}

1995 Radiocarbon Calibration and Analysis of Stratigraphy: The OxCal Program. Radiocarbon 37,2: 425-430.

2001 Development of the Radiocarbon Program OxCal. Radiocarbon 43,2A: 355-363.

BRUZEK J

2002 A Method for Visual Determination of Sex, using the Human Hip Bone. American Journal of Physical Anthropology 117: 157168.

BURIAN F. and FRIEDMAN E.

1988 A Note on the Obsidian Finds from the Pre-Pottery Neolithic B site 109 near Nahal Lavan. Mitekufat Haeven - Journal of the Israel Prehistoric Society 21: 58-59. (Hebrew)

BURIAN F., FRIEDMAN E. and MINTZ E.

1999 Nahal Lavan 109 - A Pre-Pottery Neolithic site in the Western Negev, Israel. Festschrift für Gunter Samulla. Materialien zur vor- und frühgeschichte von Hessen 8: 95-120.

\section{CAMPANA D.}

1991 Bone Implements from Hayonim Cave: Some Relevant Issues. In: BAR-YOSEF O. and VALLA F. (eds), The Natufian Culture in the Levant: 459-466. Ann Arbor: International Monographs in Prehistory.

CAUVIN J.

1968 Les outillages néolithiques de Byblos et du littoral libanais. Paris: Adrien Maisonneuve.

1980 Le Moyen-Euphrate au VIII millénaire d'après Mureybet et Cheihk Hassan. In : MARGUERON J.-Cl. (éd.), Le Moyen-
Euphrate : zone de contacts et d'échanges. Actes du colloque de Strasbourg 10-12 mars 1977 : 21-34. Leiden : Brill.

2000 The Birth of the Gods and the Origins of Agriculture. Cambridge, UK: Cambridge University Press.

CAUVIN M.-C.

1995 Les industries lithiques de Tell Aswad en Damascène. In: CONTENSON H. DE (éd.), Aswad et Ghoraife, sites néolithiques en Damascène (Syrie) aux IX et VIII ${ }^{e}$ millénaires avant l'ère chrétienne : 81-122. Beyrouth : IFAPO (B.A.H. 137).

CAUVIN M.-C. et CAUVIN J.

1993 La séquence néolithique PPNB au Levant Nord. Paléorient 19,1 : 23-28.

COQUEUGNIOT É.

2000 Dja'dé (Syrie) un village à la veille de la domestication (seconde moitié du IX ${ }^{\mathrm{e}}$ millénaire av. J.-C.). In : GuILAINE J. (éd.), Premiers paysans du monde. Naissances des agricultures : 63-79. Paris : Errance.

DAVIS S.J.M.

1983 The Age Profiles of Gazelles predated by Ancient Man in Israel: Possible Evidence for a Shift from Seasonality to Sedentism in the Natufian. Paléorient 9,1:55-62.

DUDAY H.

2005 L'archéothanatologie ou l'archéologie de la mort. In : Dutour O., Hublin J.-J. et VANDERMEERSCH B. (éd.), Objets et méthodes en paléoanthropologie: 153-207. Paris: Comité des travaux historiques et scientifiques (Orientations et méthodes 7).

EdWARdS P.C., MEAdows J.M., METZGer C. and SAYEJ G.

2002 Results from the First Season at Zahrat adh-Dhra' 2: A New PrePottery Neolithic A Site on the Dead Sea Plain in Jordan. NeoLithics 1/02: 11-16.

EDWARdS P.C., MEAdOWS J.M., SAYEJ G. and WESTWAY M

2004 From the PPNA to the PPNB: New Views from the Southern Levant after Excavations at Zahrat adh-Dhra' 2 in Jordan. Paléorient 30,2 : 21-60.

EFRAT E.

1963 Geographical Aspects in the Physical Planning of the Jerusalem Region. Jerusalem: Massada.

EISENBERG E. and SKLAR D.

2005 Motza 2000. Excavations and Surveys in Israel 117: 53

GEBEL H.G.K., MUHEISEN M., NISSEN H.J. and QADI N.

2004 Late PPNB Basta: Results of 1992. In: BIENERT H.D., GEBEL H.G.K. and NEEF R. (eds), Central Settlements in Neolithic Jordan: 21-40. Berlin: ex oriente (Studies in Early Near Eastern Production, Subsistence, and Environment 5).

GOPHER A.

1989a Horvat Galil and Nahal Bezet I: Two Neolithic Sites in the Upper Galilee. Mitekufat Haeven - Journal of the Israel Prehistoric Society 22: 82-92.

1989b The Flint Assemblages of Munhata (Israel). Paris: Association Paléorient (Les Cahiers du Centre de recherche français de Jérusalem 4$)$.

1994 Arrowheads of the Neolithic Levant. Winona Lake, Indiana: Eisenbrauns (American Schools of Oriental Research Dissertation Series 10). 
1996

What happened to the Early Pre-Pottery Neolithic B? In: KOZLOWSKI S.K. and GEBEL H.G.K. (eds), Neolithic Chipped Stone Industries of the Fertile Crescent, and their Contemporaries in Adjacent Regions: 151-158. Berlin: ex oriente (Studies in Early Near Eastern Production, Subsistence, and Environment 3).

1997 Horvat Galil-An Early PPNB site in the Upper Galilee, Israel. Tel Aviv 24,2: 183-222.

GOPHER A. and GOPHNA R.

1993 Cultures of the Eighth and Seventh Millennia B.P. in the Southern Levant: A Review for the 1990's. Journal of World Prehistory 7,3: 297-353.

GOPHER A., BARKAI R. and MARDER O.

1998 Cultural Contacts in the Neolithic Period: Anatolian Obsidian in the Southern Levant. In: OTTE M. (dir.), Préhistoire d'Anatolie : genèse de deux mondes. Actes du Colloque international, Liège 28 avril-3 mai 1997, vol. 2: 624-640. Liège: Université de Liège.

\section{GORING-MORRIS A.N. and BELFER-COHEN A.}

1997 The Articulation of Cultural Processes and Late Quaternary Environmental Changes in Cisjordan. Paléorient 23,2: 71-93.

GORING-MORRIS A.N. and HORWITZ L.K.

2007 Funerals and Feasts in the Near Eastern Pre-Pottery Neolithic B. Antiquity 81: 1-17.

GREENHUT Z.

2006 Production, Storage and Distribution of Grain during the Iron Age and their Linkage to the Socio-Economic Organization of the Settlement in Israel. Unpublished PhD Dissertation. Tel-Aviv: Tel-Aviv University.

GROOT A. DE and GREENHUT Z.

1995 Motza. Excavations and Surveys in Israel 17: 83-84.

HERSHKOVITZ I. and GOPHER A.

1988 Human Remains from Horvat Galil. A Pre-Pottery Neolithic Site in the Upper Galilee, Israel. Paléorient 14,1 : 119-123.

HORWITZ L.-K., TCHERNOV E., DUCOS P., BECKER C., DRIESCH A. VON DEN, MARTIN L. and GARRARD A.

1999 Animal Domestication in the Southern Levant. Paléorient 25,2 : 63-80.

KHALAILY H. and MARDER O.

2003 The Neolithic Site of Abu Gosh. The 1995 Excavations. Jerusalem: Israel Antiquities Authority (IAA Reports 19).

KHALAILY H., MARDER O. and BARZILAI O.

2007 An Early Pre-Pottery Neolithic B Blade Cache from Motza, West of Jerusalem, Israel. In: ASTRUC L., BINDER D. and BRIOIS F. (eds), Technical Systems and Near Eastern PPN Communities: 269-276. Antibes: Édition APDCA.

KUIJT I.

1997 Interpretation, Data, and the Khiamian of the South-Central Levant. Neo-Lithics 3: 3-6.

2003 Between Foraging and Farming: Critically Evaluating the Archaeological Evidence for the Southern Levantine Early PrePottery Neolithic B Period. Turkish Academy of Sciences - Journal of Archaeology 6: 7-25.
KUIJT I. and GORING-MORRIS A.N

2002 Foraging, Farming, and Social Complexity in the Pre-Pottery Neolithic of the Southern Levant: A Review and Synthesis. Journal of World Prehistory 16: 361-440.

KuiJT I., MABRY J. and PALUMBO G.

1991 Early Neolithic Use of Upland Areas of Wadi El-Yabis: Preliminary Evidence from the Excavations of 'Irak Ed-Dubb, Jordan. Paléorient 17,1 : 99-108.

LECHEVALLIER M.

1978 Abou Gosh et Beisamoun: deux gisements du VII millénaire avant l'ère chrétienne en Israël. Paris: Association Paléorient (Mémoires et Travaux du Centre de recherches français de Jérusalem 2).

LE DOSSEUR G.

2006 La Néolithisation au Levant Sud à travers l'exploitation des matières osseuses. Étude techno-économique de onze séries d'industries osseuses du Natoufien au PPNB récent. Thèse de doctorat non publiée. Paris : Université Paris I Panthéon-Sorbonne.

LE MORT F.

1992 Les pratiques funéraires des populations du Levant au début du Néolithique. Archéo-nil 2: 37-42.

1994 Les sépultures. In : LECHEVALLIER M. et RONEN A. (éd.), Le gisement de Hatoula en Judée occidentale, Israël: 39-57. Paris : Association Paléorient (Mémoires et Travaux du Centre de recherche français de Jérusalem 8 ).

MARDER O. and KHALAILY H.

2004 New Epipalaeolithic Remains in Jerusalem and Judean Mountains. (Hebrew) In: BARUCH E. and FAUST A. (eds), New Studies on Jerusalem 10: 7-11. Ramat-Gan: The Ingeburg Rennert Center for Jerusalem Studies Publications.

MARKUS M.

1993 Jerusalem Mountains - Description and Travel. Tel Aviv: Academic press.

MARSHAL D.M.

1982 Jericho Bone Tools and Objects. In: KENYON K.M. and HOLLAND T.A. (eds), Excavations at Jericho IV: 570-622. London: British School of Archaeology in Jerusalem.

MOORREES C.F.A., FANNING E.A.A. and HunT E.E. Jr.

1963a Formation and Resorption of three Deciduous Teeth in Children. American Journal of Physical Anthropology 21: 205-213.

1963b Age Variation of Formation Stages for Ten Permanent Teeth. Journal of Dental Research 42: 1490-1502.

MUNRO N.D.

2004 Zooarchaeological Measures of Hunting Pressure and Occupation Intensity in the Natufian. Current Anthropology 45: S5-S34

NADEL D.

1997 The Chipped Stone Industry of Netiv Hagdud. In: BARYOSEF O. and GOPHER A. (eds), An Early Neolithic Village in the Jordan Valley. Part I: The Archaeology of Netiv Hagdud: 71-150. Cambridge, MA: Harvard University, Peabody Museum of Archaeology and Ethnology.

QUINTERO L.A.

1996 Flint Mining in the Pre-Pottery Neolithic: Preliminary Report on the Exploitation of Flint at Neolithic 'Ain Ghazal in Highland Jordan. In: KOZLOWSKI S.K. and GEBEL H.G.K. (eds), Neolithic Chipped Lithic Industries of the Fertile Crescent and their Adja- 
cent Regions: 233-260. Berlin: ex oriente (Studies in Early Near Eastern Production, Subsistence, and Environment 3).

REIMER P.J., BAILLIE M.G.L., BARD E., BAYLISS A., BECK W.J., BERTRAND C., BLACKWELl P.G., BUCK C.E., BURR G.S., CUTLER K.B., DAMON P.E., EDWARDS R.L., FAIRBANKS R.G., FRIEDRICH M., GUILDERSON T.P., HUGHEN K.A., KROMER B., MCCORMAC F.G., MANNING S., BRONK RAMSEY C., REIMER R.W., REMMELE S., SOUTHON J.R., STUIVER M., TALAMO S., TAYLOR F.W., VAN DER PLICHT J. and WEYHENMEYER C.E.

2003 INTCAL04: Calibration Issue. Radiocarbon 46,1: 1029-1058.

\section{ROLLEFSON G.O.}

1983 Ritual and Ceremony at Neolithic 'Ain Ghazal (Jordan). Paléorient $9,2: 29-38$.

1998 The Aceramic Neolithic. In: HENRY D.O. (ed.), The Prehistoric Archaeology of Jordan: 102-126. Oxford (BAR Int. Ser. 705).

2001 The Neolithic Period. In: MACDONALD B., ADAMS R. and BIENKOWSKI P. (eds), The Archaeology of Jordan: 67-105. Sheffield: Sheffield Academic Press.

\section{ROLLEFSON G.O. and SIMMONS A.H.}

1985 The Early Neolithic Village of 'Ain Ghazal, Jordan: Preliminary Report on the 1983 Season. Bulletin of the American School of Oriental Research, Supplement 23: 35-52.

1986 The Neolithic Village of 'Ain Ghazal, Jordan: Preliminary Report on the 1985 Season. Bulletin of the American School of Oriental Research, Supplement 25: 93-106.

RONEN A.

1988 Sefunim Prehistoric Site, Mount Carmel, Israel. Oxford (BAR Int. Ser. 230).

SAPIR-HEN L., BAR-OZ G., KHALAILY H. and DAYAN T.

in prep. The Last of the Gazelle Hunters in the Southern Levant: the Neolithic Site of Motza, Israel.

\section{SHALEM N.}

1928 Motza. In: SUKEINIK A.L. and PERES Y. (eds), Yerushalem: 1-6. Jerusalem: Yidiot. (Hebrew)

1937 Nota priliminare su alcuni nuivi giacimenti preistorici in Palestina. Archivio per l'Antropologia e la Etnologia LXVII: 123139.

\section{STORDEUR D.}

1999

Reprise des fouilles préhistoriques à Cheikh Hassan : une campagne de reconnaissance. Annales archéologiques arabes syriennes XLIII: 59-64.
2003 Tell Aswad. Résultats préliminaires des campagnes 2001 et 2002. Neo-Lithics 1/03: 7-15.

STORDEUR D. et ABBÈs F.

2002 Du PPNA au PPNB : mise en lumière d'une phase de transition à Jerf el Ahmar (Syrie). Bulletin de la Société préhistorique française 99,03 : 563-595.

\section{STUART-MACADAM P.}

1992 Anemia in Past Human Population. In: STUART-MACADAM P. and KenT S. (eds), Diet, Demography and Disease. Changing Perspectives on Anemia: 151-170. New York: Aldine de Gruyter.

STUIVER M. and POLACH H.A.

1977 Discussing Reporting ${ }^{14} \mathrm{C}$ Data. Radiocarbon 19,3: 255.

TUBB K.W. and GRISSOM C.A.

1995 Ayn Ghazal: A Comparative Study of the 1983 and 1985 Statuary Caches. Studies in the History and Archaeology of Jordan V: 437-447.

Valla F.R., Valentin B., Khalaily H., Valladas H., TeSneratLABORDE N., SAMUELIAN N., BOCQUENTIN F., RABINOVICH R., BRIDAUlT A., SIMMONS T., LE DOSSEUR G., ROSEN A., DUBREUIL L., BAR-YOSEF D.-M. and BELFER-COHEN A.

$2004 \quad$ Les fouilles de Mallaha en 2000 et 2001. $3^{e}$ rapport préliminaire. Mitekufat Haeven - Journal of the Israel Prehistoric Society 34: 49-244.

\section{VAN KLINKEN G.J.}

1999 Bone Collagen Quality Indicators for Paleodietry and Radiocarbon Measurements. Journal of Archaeological Science 26: 687695.

WILKE P.

1996 Bullet-Shaped Micro-Blade Cores of the Near Eastern Neolithic: Experimental Replicative Studies. In: KOZLOWSKI S.K. and GEBEL H.G.K. (eds), Neolithic Chipped Stone Industries of the Fertile Crescent, and their Contemporaries in Adjacent Regions: 289-310. Berlin: ex oriente (Studies in Early Near Eastern Production, Subsistence, and Environment 3).

YIZHAQ M.

2004 Characterizing and Dating of the Early PPNB Layer at the site of Motza. Unpublished M.Sc. Rehovot: Weizmann Institute of Science.

YiZhaQ M., MintZ G., COHEN I., Khalaily H., Weiner S. and BOARETTO E.

2005 Quality Controlled Radiocarbon Dating of Bones and Charcoal from the Early Pre-Pottery Neolithic B (PPNB) of Motza (Israel). Radiocarbon 47: 193-206. 
